\title{
The Influence of ppb Levels of Chloride Impurities on the Stress Corrosion Crack Growth Behaviour of Low-Alloy Steels under Simulated Boiling Water Reactor Conditions
}

\author{
H.P. Seifert*, S. Ritter \\ Paul Scherrer Institute (PSI) \\ Nuclear Energy and Safety Research Department \\ Laboratory for Nuclear Materials \\ 5232 Villigen PSI, SWITZERLAND \\ e-mail: hans-peter.seifert@psi.ch \\ Tel: +415631044 02, Fax: +41563102199
}

\begin{abstract}
The effect of chloride on the stress corrosion crack (SCC) growth behaviour in low-alloy reactor pressure vessel steels was evaluated under simulated boiling water reactor conditions. In normal water chemistry environment, ppb-levels of chloride may result in fast SCC after rather short incubation periods of few hours. After moderate and short-term chloride transients, the SCC crack growth rates return to the same very low high-purity water values within few 100 hours. Potential long-term (memory) effects on SCC crack growth cannot be excluded after severe and prolonged chloride transients. The chloride tolerance for SCC in hydrogen water chemistry environment is much higher.
\end{abstract}

Key words: Low-alloy steel, stress corrosion cracking, chloride, reactor conditions

This document is the accepted manuscript version of the following article:

Seifert, H. P., \& Ritter, S. (2016). The influence of ppb levels of chloride impurities on the stress corrosion crack growth behaviour of low-alloy steels under simulated boiling water reactor conditions. Corrosion Science, 108, 134-147. https://doi.org/10.1016/j.corsci.2016.03.001

This manuscript version is made available under the CC-BY-NC-ND 4.0 license http://creativecommons.org/licenses/by-nc-nd/4.0/ 


\section{List of Abbreviations}

AL

ASTM

ASTM E399

BWR

BWRVIP

CGR

CF

CL

C(T)

DCPD

DL

DMW

DH

DO

DSA

EAC

ECP

ENSI

EPRI

F\&A

FL

FRAD

GE GR

HAZ

HP

HWC

LAS

NMCA

NRC

NWC

ppb

ppm

PPU

PSI

PWHT

PWR

$\mathbf{Q}$

R

RL

RPV

SCC

SEM

SICC

SHE

SR

SS

SSY

$T$

YS
Action Level of EPRI Water Chemistry Guidelines

American Society of Testing and Materials Standards

Test method for plane-strain fracture toughness of metallic materials

Boiling water reactor

Boiling Water Reactor Vessel and Internals Program of EPRI

Crack growth rate

Corrosion fatigue

Constant load

Compact tension specimen

Direct current potential drop crack length measurement method

SCC Disposition Line (EPRI BWRVIP-60)

Dissimilar metal weld

Dissolved hydrogen (content)

Dissolved oxygen (content)

Dynamic strain ageing

Environmentally-assisted cracking

(Free) electrochemical corrosion potential

Swiss Nuclear Safety Inspectorate, Switzerland

Electric Power Research Institute

Ford \& Andresen (EAC model)

Fusion line

Film rupture anodic dissolution crack growth mechanism

General Electric Global Research

Weld heat-affected zone

High-purity (water)

Hydrogen water chemistry

Low-alloy steel

Noble metal chemical addition

National Regulatory Commission, USA

Normal water chemistry

Parts per billion by weight, $1 \mathrm{ppb}=1 \mu \mathrm{g} / \mathrm{kg}$

Parts per million by weight, $1 \mathrm{ppm}=1 \mathrm{mg} / \mathrm{kg}$

Periodical partial unloading

Paul Scherrer Institut, Switzerland

Post-weld heat treatment

Pressurised water reactor

Quenched

Load ratio

Rising load

Reactor pressure vessel

Stress corrosion cracking

Scanning electron microscope

Strain-induced corrosion cracking

Standard hydrogen electrode

Stress-relieved

Stainless steel

Small-scale yielding

Tempered

Yield stress 


\section{Introduction}

The reactor pressure vessel (RPV) is the most critical component of light water reactors with regard to safety and lifetime [1, 2]. Under the simultaneous effect of the reactor coolant, thermo-mechanical operational loads and irradiation, cracks can initiate and grow in the RPV during service by environmentally-assisted cracking (EAC) and thermo-mechanical fatigue. Important examples from the field are, e.g., the RPV feedwater nozzle corner cracking by thermo-mechanical fatigue and EAC in boiling water reactors (BWR) [1, 2] or the stress corrosion cracking (SCC) in RPV penetration and attachment welds in BWRs and pressurized water reactors (PWR) [3, 4]. Fabrication- or welding-induced incipient cracks (e.g., hot and relaxation cracks in the cladding or cladding/RPV interface) were observed in few isolated cases. Furthermore, the toughness and ductility of the RPV steel can decrease with time due to irradiation embrittlement, thermal ageing or potential (corrosive) reactor coolant (e.g., hydrogen) effects $[5,6]$.

An accurate knowledge on the degradation of the toughness and fracture properties of these materials during service and of the system conditions which may lead to EAC and thermo-mechanical fatigue initiation and growth are thus evidently indispensable to ensure the safe and economic long-term operation in this context. Reliable quantitative experimental data on these phenomena and a basic knowledge on the underlying mechanisms are essential to evaluate their possible effects on structural integrity/safety and lifetime of components, to set-up adequate inspection intervals, to identify critical component locations/operating conditions and to define and qualify possible mitigation, repair and maintenance actions.

The SCC [7], strain-induced corrosion cracking (SICC) [8] and corrosion fatigue (CF) [9] crack growth behaviour of different low-alloy RPV steels and weldments/heat-affected zones (HAZ) and the SCC crack growth behaviour in the Alloy 182-RPV steel transition region of dissimilar metal welds (DMW) $[3,4]$ under BWR normal water (NWC) and hydrogen water chemistry (HWC) conditions as well as the role of dynamic strain ageing (DSA) in EAC of low-alloy steels (LAS) [7, 10] was therefore investigated at Paul Scherrer Institut (PSI) in detail in the last two decades. Currently, these investigations are extended to potential high-temperature water and hydrogen effects on the fracture toughness and tearing resistance of RPV steels [5, 6].

SCC crack growth in RPV steels: The SCC behaviour of low-alloy steel (LAS) pressure boundary components under transient-free, steady-state BWR power operation conditions, which covers the largest part of the lifetime, is well established $[1,2,7]$. These lab investigations revealed that LAS and their HAZs have a very high resistance to SCC growth (with small crack growth rates $<0.6 \mathrm{~mm} /$ year) in chloride-free BWR environment at temperatures of 270 to $290{ }^{\circ} \mathrm{C}$ up to very high stress intensity factor levels of $60 \mathrm{MPa} \cdot \mathrm{m}^{1 / 2}$. Critical water chemistry (e.g., chloride impurities and high corrosion potential $(E C P)$ ), loading (e.g., ripple loading) and material (e.g., hardness > $350 \mathrm{HV}$, high DSA susceptibility and intermediate temperatures) conditions that can result in sustained and fast ( $>10 \mathrm{~mm} /$ year for $K_{I}<60$ $\mathrm{MPa} \cdot \mathrm{m}^{1 / 2}$ ) SCC under BWR/NWC conditions were identified, but many of them generally appeared atypical for current optimized BWR power operation practice or modern, properly fabricated RPVs.

These lab experiments also formed the basis for the definition of disposition lines for crack growth due to SCC (Figure 1) which were proposed by the Electric Power Research Institute (EPRI) as an interim disposition rationale and subsequently accepted by the US NRC [11]. Disposition Line 1 (DL 1) considers crack growth under constant load in BWR environments during transient-free steady-state power operation. Disposition Line 2 (DL 2), which is equivalent to the so called "low-sulphur crack growth curve" of the Ford \& Andresen model [12], is regarded as the bounding curve for SCC CGRs during and $100 \mathrm{~h}$ after transients in water chemistry. Approximate $K_{I}$-ranges for different important BWR RPV crack configurations (cracked cladding and crack in RPV shell with a depth of $25 \%$ of the wall 
thickness (T/4 crack) or cracks in Alloy 182 attachment/penetrations welds with crack-tips in the Alloy 182/RPV interface) are also shown in Figure 1 as shaded areas.

Water chemistry transients: Variations in water chemistry may periodically (e.g., conductivity/impurity and oxygen/ECP transients during start-up/shut-down) or occasionally (ion exchanger resin intrusions or condenser leakages during steady-state power operation) occur in nuclear power plants. Nowadays the extent (magnitude, period) and frequency of such variations is strongly minimized, e.g., by following the current EPRI BWR Water Chemistry Guidelines (Table 1) [13]. Nevertheless, the possible effect of short-term water chemistry transients on the transition EAC crack growth behaviour during, and in particular after a transient under subsequent steady-state power operation is of great interest for safety assessments. In the past, the focus was placed on the effect of water chemistry transients on SCC in stainless steels [14-18] and these investigations clearly revealed that low concentration levels of sulphate and chloride (> 5 to $10 \mathrm{ppb}$, ppb: parts per billion by weight, $1 \mathrm{ppb}=1 \mu \mathrm{g} / \mathrm{kg}$ ) can result in significant acceleration of SCC crack growth in BWR/NWC environment. On the other hand, there is an obvious lack of qualified and well documented testing with chloride impurities for RPV steels under BWR conditions.

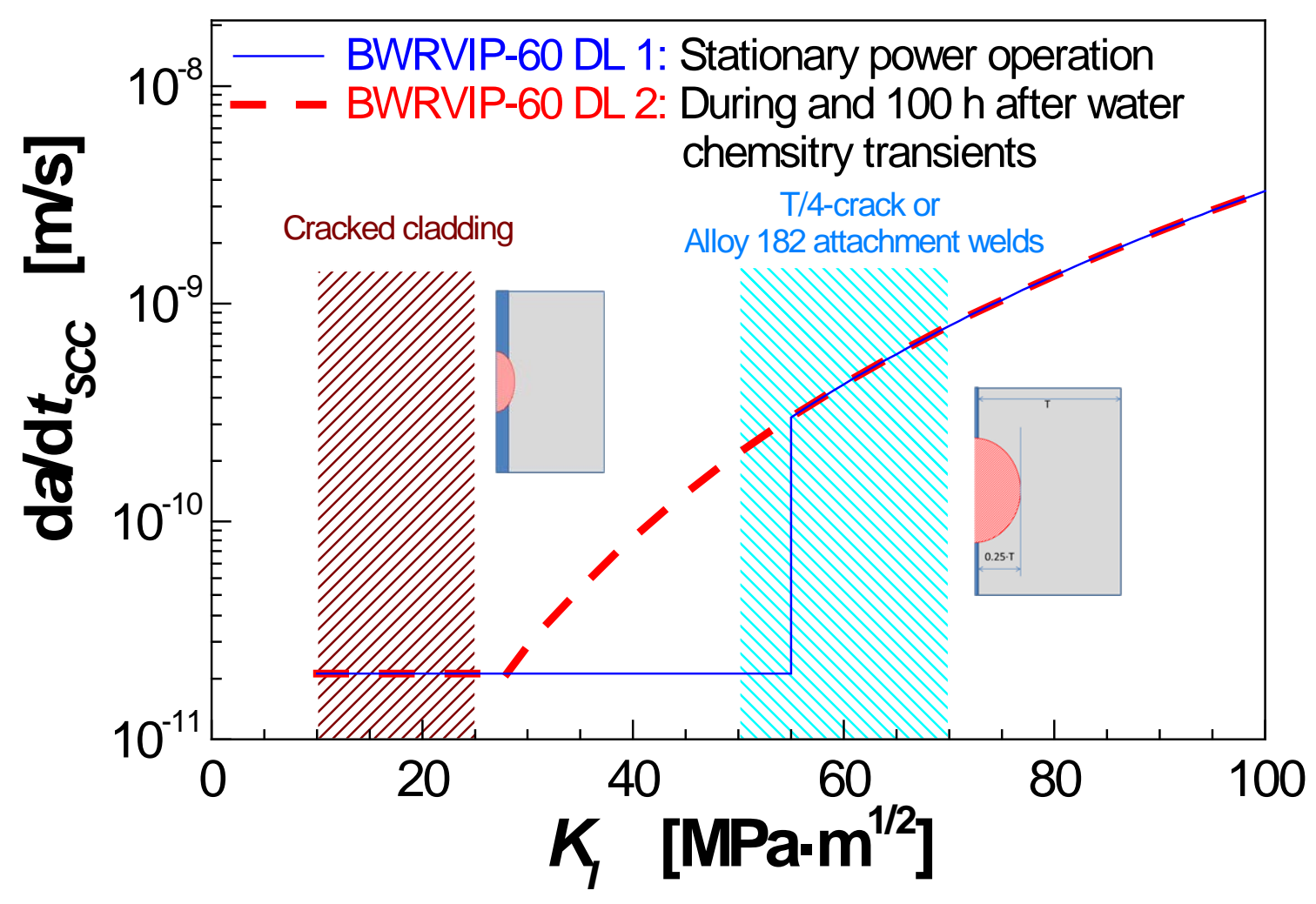

Figure 1: BWRVIP-60 Disposition Lines (DL) [11] for SCC crack growth in LAS. Line 1: Stationary, transient-free BWR power operation (< EPRI Action Level 1), line 2: During and $100 \mathrm{~h}$ after water chemistry transients (> EPRI Action Level 1). Typical $\mathrm{K}_{\mathrm{I}}$-ranges for different crack configurations in BWR RPV as shaded regions (T/4 crack: Crack depth $=25 \%$ of wall thickness). 
Table 1: EPRI Water Chemistry Guideline recommendations for the reactor water during stationary BWR power operation for BWR NWC conditions) [13].

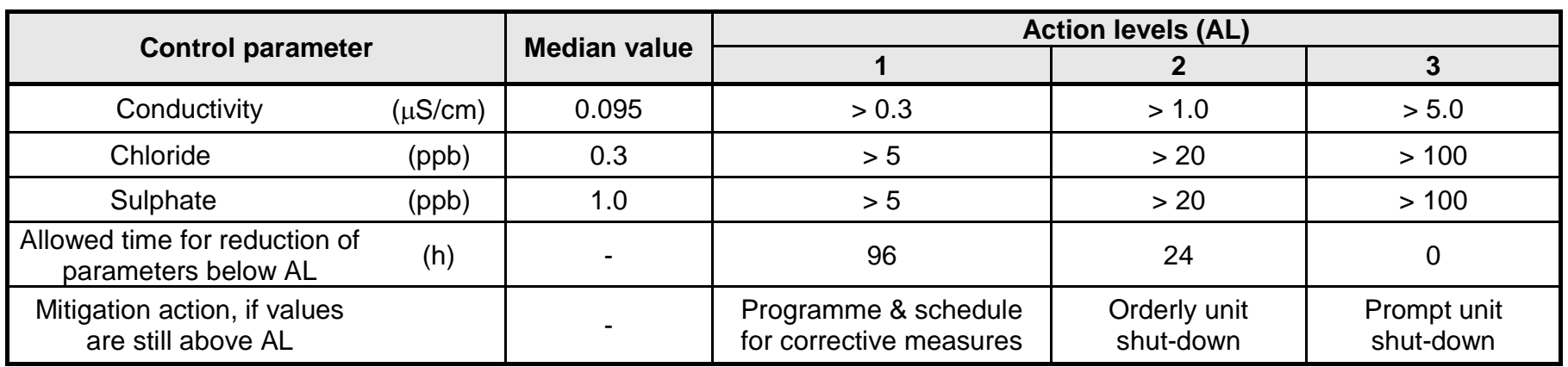

Therefore, the SCC crack growth behaviour of six low-alloy RPV steels during and after addition of chloride was investigated under simulated BWR NWC and HWC power operation conditions. These tests should indicate, if hysteresis or long-term effects might occur and reveal information on the transition behaviour during and after chloride transients (Figure 2). Furthermore, the adequacy and conservative character of the BWRVIP-60 SCC Disposition Line 2 [11] for SCC crack growth in LAS during and after water chemistry transients was evaluated and assessed in the context of the EPRI BWR Water Chemistry Guidelines (Table 1) [13].

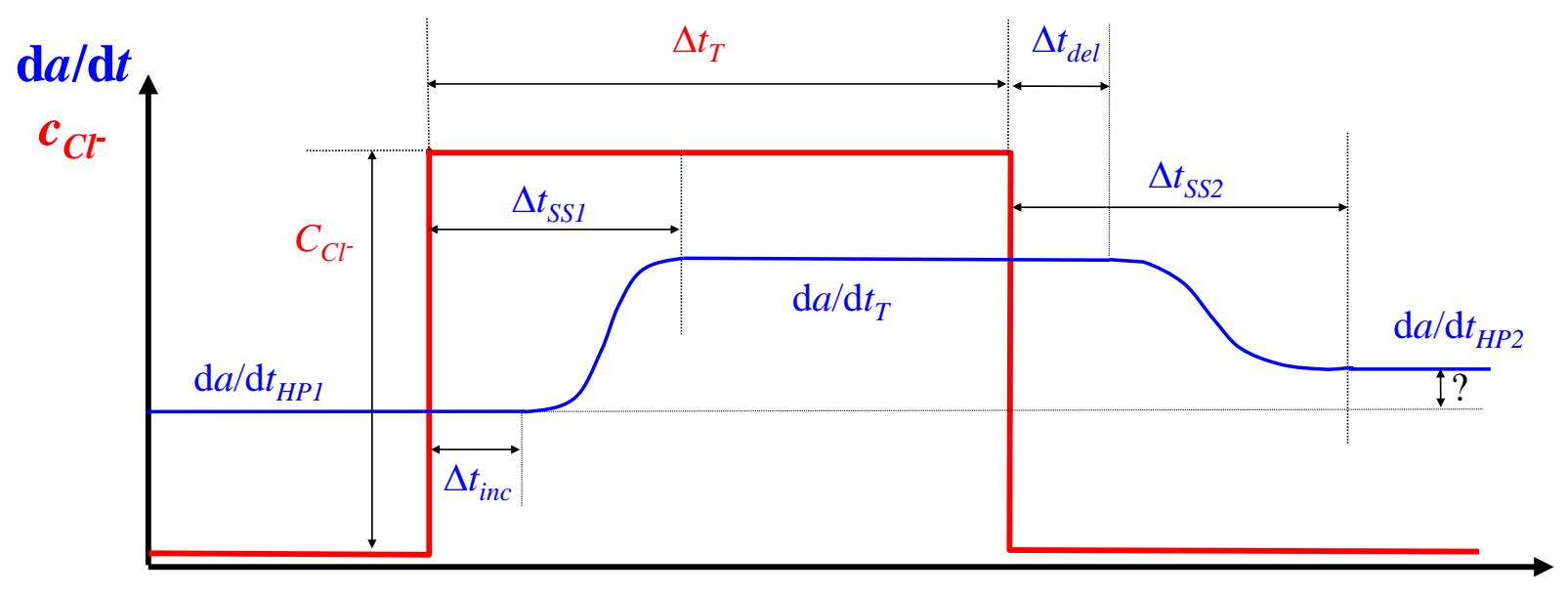

Time $t$

- Thresholds $\Delta t_{T}\left(c_{C l}\right)$ and $c_{C I^{-}}\left(\Delta t_{T}\right)$ for acceleration of SCC?

- Response times: $\quad \Delta t_{i n c}, \Delta t_{s s 1}, \Delta t_{d e l}, \Delta t_{\text {ss2 }}$

- EAC acceleration factor: $\quad\left(\mathrm{d} a / \mathrm{d} t_{T} / \mathrm{d} a / \mathrm{d} t_{H P 1}\right)>1$ ?

- Hysteresis/long-term effects: $\mathrm{da} / \mathrm{d} t_{H P 2} / \mathrm{da} / \mathrm{d} t_{H P 1}>1$ ?

- Asymmetry effects: $\Delta t_{\mathrm{ss} 2}>\Delta t_{\mathrm{ss} 1}$ ?

Figure 2: Schematic of SCC behaviour during a chloride transient.

The present paper summarizes the results of these tests. Related PSI investigations on the effect of chloride on EAC initiation [19] and on corrosion fatigue and SICC crack growth [20] are summarized in two other papers. After a brief overview on the investigated materials and applied experimental procedure in Section 2, the SCC behaviour during and after chloride transients is discussed in Sections 3.1 and 3.2 for BWR NWC and HWC environment, respectively. The adequacy and conservative character of the 
EPRI BWR Water Chemistry Guidelines and BWRVIP-60 SCC Disposition Line 2 for SCC crack growth in LAS during and after chloride transients in the light of these observations is evaluated in Section 3.3. Finally, a tentative mechanistic explanation for the tremendous effect of chloride on SCC in LAS in oxygenated high-temperature water is elaborated based on the film rupture anodic/dissolution mechanism [12, 21] and crevice chemistry models [22-24] in Section 3.4.

\section{Materials and Experimental Procedure}

\subsection{Materials and Specimens}

Several different types of low-alloy, nuclear grade RPV steels were investigated (Table 2). The investigated materials are characteristic for RPVs of Western light water reactors. The specimens were fabricated either directly from the forged ingots and hot-rolled steel plates [9] or from simulated Alloy 182-RPV steel dissimilar metal joints [4] of the corresponding steels (Table 3). The corresponding chemical compositions are given in Tables 4 and 5. Concerning the EAC behaviour, the steels mainly differed in their susceptibility to DSA and sulphur content/MnS morphology.

Table 2: Investigated low-alloy RPV steels $(\mathrm{Q}=$ quenched, $\mathrm{T}=$ tempered, $\mathrm{SR}=$ stress relieved, $\mathrm{PWHT}$ = post-weld heat treated, DSA = dynamic strain ageing).

\begin{tabular}{|c|c|c|c|c|c|c|}
\hline \multicolumn{2}{|c|}{ Materials } & $\begin{array}{c}\text { S } \\
{[\text { wt.\%] }}\end{array}$ & $\begin{array}{c}\text { Heat } \\
\text { treatment }\end{array}$ & Microstructure & $\begin{array}{c}\text { YS } \text { 288 }^{\circ} \mathrm{C} \\
{[\mathrm{MPa}]}\end{array}$ & $\begin{array}{c}\text { DSA- } \\
\text { suscept. }\end{array}$ \\
\hline 20 MnMoNi 5 5 & A & 0.004 & Q+T & Bainitic & 418 & high \\
\hline SA 508 Cl. 2 & B & 0.004 & Q+T & $\begin{array}{c}\text { Bainitic/ferritic- } \\
\text { pearlitic }\end{array}$ & 396 & high \\
\hline SA 533 B Cl. 1 & C & 0.018 & N, Q+T, SR & Bainitic & 412 & medium \\
\hline 22 NiMoCr 3 7 & D & 0.007 & Q+T, PWHT & Bainitic & 400 & low \\
\hline 20 MnMoNi 5 5 & E & 0.015 & Q+T, PHWT & Bainitic & 438 & medium \\
\hline SA 508 Cl. 2 & F & 0.016 & Q+T, PHWT & Bainitic & 440 & medium \\
\hline
\end{tabular}

Table 3: Overview on the fabricated Alloy 182- RPV steel DMWs.

\begin{tabular}{|c|c|c|c|c|c|c|c|c|c|}
\hline Weld & PWHT & $\begin{array}{c}\text { Weld } \\
\text { Filler }\end{array}$ & $\begin{array}{c}\text { HV0.1 } \\
\text { bulk WM }\end{array}$ & Low-Alloy RPV Steel & $\begin{array}{c}\text { S } \\
\text { [wt.\%] }\end{array}$ & $\begin{array}{c}\text { YS 288 } \\
{[\mathrm{MPa}]}\end{array}$ & $\begin{array}{c}\text { DSA } \\
\text { suscept. }\end{array}$ & $\begin{array}{c}\text { Peak HV0.1 } \\
\text { LAS HAZ }\end{array}$ \\
\hline Weld A & yes & Alloy 182 & $200-220$ & SA 508 Cl. 2 & F & 0.016 & 440 & medium & $280-320$ \\
\hline Weld B & buffer layer only & Alloy 182 & $280-320$ & SA 533 B Cl. 1 & C & 0.018 & 396 & medium & $340-360$ \\
\hline Weld C & buffer layer only & Alloy 182 & $300-320$ & 20 MnMoNi 5 5 & A & 0.004 & 418 & high & $380-400$ \\
\hline Weld D & buffer layer only & Alloy 182 & $320-340$ & 22 NiMoCr 3 7 & D & 0.007 & 412 & low & $380-410$ \\
\hline
\end{tabular}

Table 4: Chemical composition in wt.\% of investigated low-alloy RPV steels.

\begin{tabular}{|c|c|c|c|c|c|c|c|c|c|c|c|c|}
\hline \multicolumn{1}{|c|}{ Material } & C & Si & Mn & P & S & Cr & Mo & Ni & V & Al & Cu \\
\hline 20 MnMoNi 5 5 & A & 0.21 & 0.25 & 1.26 & 0.004 & 0.004 & 0.15 & 0.5 & 0.77 & 0.008 & 0.013 & 0.06 \\
\hline SA 508 Cl. 2 & B & 0.21 & 0.27 & 0.69 & 0.005 & 0.004 & 0.38 & 0.63 & 0.78 & 0.006 & 0.015 & 0.16 \\
\hline SA 533 B Cl. 1 & C & 0.25 & 0.24 & 1.42 & 0.006 & 0.018 & 0.12 & 0.54 & 0.62 & 0.007 & 0.03 & 0.15 \\
\hline 22 NiMoCr 3 7 & D & 0.215 & 0.20 & 0.91 & 0.008 & 0.007 & 0.42 & 0.53 & 0.88 & 0.007 & 0.018 & 0.04 \\
\hline 20 MnMoNi 5 5 & E & 0.26 & 0.32 & 1.44 & 0.016 & 0.015 & 0.15 & 0.61 & 0.63 & 0.02 & 0.029 & 0.17 \\
\hline SA 508 Cl. 2 & F & 0.200 & 0.12 & 0.93 & 0.010 & 0.016 & 0.45 & 0.59 & 0.91 & - & 0.009 & 0.03 \\
\hline
\end{tabular}


Table 5: Chemical composition in wt.\% of weld metal (as deposited) and RPV steel of the DMWs.

\begin{tabular}{|c|c|c|c|c|c|c|c|c|c|c|c|c|c|c|c|}
\hline \multicolumn{2}{|r|}{ Material } & C & $\mathrm{Ni}$ & $\mathrm{Cr}$ & $\mathrm{Fe}$ & $\mathbf{P}$ & $\mathbf{s}$ & Mn & Mo & $\mathrm{Si}$ & $\mathrm{Ti}$ & $\begin{array}{c}\mathrm{Nb+} \\
\mathrm{Ta}\end{array}$ & Al & Co & $\mathrm{Cu}$ \\
\hline \multirow{2}{*}{$\begin{array}{l}\varangle \\
\frac{0}{0} \\
3\end{array}$} & Alloy 182 & 0.043 & 71.6 & 15.1 & 8.3 & 0.002 & $\begin{array}{l}0.007- \\
0.014 \\
\end{array}$ & 2.85 & 0.45 & 0.20 & 0.027 & 2.19 & - & 0.040 & 0.01 \\
\hline & SA $508 \mathrm{Cl} .2$ & 0.200 & 0.91 & 0.45 & 96.2 & 0.010 & 0.016 & 0.93 & 0.59 & 0.12 & - & - & 0.009 & 0.012 & 0.03 \\
\hline \multirow{2}{*}{$\begin{array}{l}\infty \\
\frac{0}{0} \\
3\end{array}$} & Alloy 182 & 0.029 & 69.0 & 15.5 & 5.93 & 0.002 & 0.005 & 6.27 & 0.18 & 0.56 & 0.083 & 2.38 & 0.028 & 0.017 & 0.01 \\
\hline & SA 533 B Cl.1 & 0.250 & 0.62 & 0.12 & 96.6 & 0.006 & 0.018 & 1.42 & 0.54 & 0.24 & - & - & 0.030 & - & 0.15 \\
\hline \multirow{2}{*}{$\frac{u}{\frac{0}{0}}$} & Alloy 182 & 0.030 & 69.1 & 15.5 & 6.07 & $<0.002$ & 0.004 & 6.18 & 0.18 & 0.54 & 0.067 & 2.28 & 0.022 & 0.014 & 0.01 \\
\hline & 20 MnMoNi 55 & 0.210 & 0.77 & 0.15 & 96.8 & 0.004 & 0.004 & 1.26 & 0.50 & 0.25 & - & - & 0.013 & - & 0.06 \\
\hline \multirow{2}{*}{$\begin{array}{l}0 \\
\frac{0}{0} \\
3\end{array}$} & Alloy 182 & 0.042 & 69.5 & 15.9 & 5.11 & 0.003 & 0.005 & 6.23 & 0.18 & 0.55 & 0.077 & 2.34 & 0.024 & 0.014 & 0.007 \\
\hline & 22 NiMoCr 37 & 0.215 & 0.88 & 0.42 & 96.8 & 0.008 & 0.007 & 0.91 & 0.53 & 0.2 & - & - & 0.018 & - & 0.04 \\
\hline
\end{tabular}

All materials were quenched and tempered. Some steels were post-weld heat-treated or stress relieved. The RPV steels had a granular, bainitic (alloy A, C, D, E, F) or a mixed bainitic/ferritic-pearlitic structure (alloy B) with an average former austenitic grain size of 10 to $20 \mu \mathrm{m}$. The spatial distribution and morphology of the MnS inclusions was fairly homogeneous and similar in alloys A to D covering the range from small spherical to large (up to a few $100 \mu \mathrm{m}$ ) elongated inclusions. Alloy E revealed distinct banded sulphur segregation zones with large clusters of MnS inclusions.

$25 \mathrm{~mm}$ thick compact tension specimens (1T C(T)) according to ASTM E399 were used for all experiments. The specimens were manufactured from forged ingots or hot-rolled steel plates mainly in T-L or L-T orientation and in T-L, T-S and S-T orientation for the DMWs specimens, respectively. The specimens were pre-cracked by fatigue in air at room temperature, using a load ratio $R$ of 0.1 . The maximal $K_{I}$ at the final load step was $\leq 15 \mathrm{MPa} \cdot \mathrm{m}^{1 / 2}$. The crack plane in the DMW specimens was perpendicular to the fusion boundary and the pre-crack tip located in the Alloy 182 weld metal [4]. The DMW tests thus started with an actively growing intergranular SCC crack in the Alloy 182 weld metal [4].

\subsection{Experimental Procedure}

The SCC tests were performed in $10 \mathrm{l}$ stainless steel autoclaves with integrated electromechanical loading systems, which were attached to sophisticated refreshing high-temperature water loops [7]. During the experiments all important mechanical (load, pull rod stroke) and environmental parameters (dissolved oxygen $(D O)$, dissolved hydrogen $(D H), \kappa, T, p$, flow, etc.) were recorded continuously. The ECP of the specimens and the redox potential (platinum probe) were monitored by use of a $\mathrm{Cu} / \mathrm{Cu}_{2} \mathrm{O} / \mathrm{ZrO}_{2}$-membrane reference electrode. Ionic impurities of the water (inlet and outlet) were analysed by Inductive Coupled Plasma - Atomic Emission Spectroscopy and Ion Chromatography. Two air fatigue pre-cracked 1T C(T) specimens were simultaneously tested in a "daisy chain". The crack advance was continuously monitored using the reversed direct current potential drop (DCPD) method with a resolution limit of about $1 \mu \mathrm{m}$. After the tests all specimens were broken open at liquid nitrogen temperature for fractographical analysis in the scanning electron microscope (SEM).

BWR conditions were mostly simulated with high-purity water (inlet conductivity $\kappa_{25^{\circ} \mathrm{C}}=0.055 \mu \mathrm{S} / \mathrm{cm}$ ) at a temperature of 274 or $288{ }^{\circ} \mathrm{C}$ (or $250{ }^{\circ} \mathrm{C}$ in one case) under low-flow conditions (4 to 5 autoclave exchanges per hour) with a local flow rate of some few $\mathrm{mm} / \mathrm{s}$. For NWC conditions, the ECP (DO content) was varied between -100 (50 ppb DO) and $+150 \mathrm{mV}_{\mathrm{SHE}}(8000 \mathrm{ppb}$ DO). A DO content of $400 \mathrm{ppb}\left(E C P=+50 \mathrm{mV}_{\text {SHE }}\right.$, redox potential $\left.=+250 \mathrm{mV}_{\mathrm{SHE}}\right)$ represents the total oxidant concentration in the reactor water during BWR steady-state power operation in a realistic way. The increased $D O$ value 
of $8000 \mathrm{ppb}(E C P=+150 \mathrm{mV}$ SHE, redox potential $=+290 \mathrm{mV}$ SHE $)$ was applied to achieve a realistic ECP for a surface crack penetrating the stainless steel cladding on the RPV wall/nozzles. The ECP of the DMW specimens in NWC environment were usually 20 to $30 \mathrm{mV}$ higher than in homogeneous RPV steel specimens. HWC conditions were simulated with a $D H$ content of $150 \mathrm{ppb}\left(E C P=-550 \mathrm{mV} \mathrm{V}_{\text {SHE }}\right)$. Depending on $D O$ level and loop system, the outlet conductivity varied between $0.06 \mu \mathrm{S} / \mathrm{cm}(0.05$ to 0.4 ppm $D O, \mathrm{ppm}=$ parts per million by weight, $1 \mathrm{ppm}=1 \mathrm{mg} / \mathrm{kg}$ ) and 0.07 to $0.09 \mu \mathrm{S} / \mathrm{cm}$ (2 to $8 \mathrm{ppm} D O$ ) and the slight higher outlet conductivity was mainly caused by chromate release by corrosion of the stainless steel pipings and autoclave. In HWC environment, the outlet conductivity was $<0.06 \mu \mathrm{S} / \mathrm{cm}$.

3 to $100 \mathrm{ppb}$ of chloride, in terms of $\mathrm{NaCl}$ or $\mathrm{HCl}$, were added to the high-purity water, either for a certain period of time only (to simulate transients), or in some cases for the whole duration of the tests. The chloride addition was controlled by the conductivity in the inlet water and checked by periodic analysis by Ion Chromatography. An excellent correlation between calculated theoretical and measured chloride values was observed. For a given chloride content, the behaviour basically was the same for $\mathrm{NaCl}$ and $\mathrm{HCl}$, thus in the following no further differentiation is made between them.

The different phases of the SCC experiments and loading conditions are schematically shown in Figure 3. The specimens were first pre-oxidized in the test environment at a small constant pre-load for one week. Then in all tests a cyclic loading phase with a positive saw tooth waveform (slow loading, fast unloading) with a constant load amplitude was applied to obtain an actively growing EAC crack before switching to pure constant load or periodical partial unloading (PPU). For the PPU a load ratio $R$ of 0.7 with a decline/rise time of 200 and $1000 \mathrm{~s}$ and a constant load period of 12 or 24 hours was used. In some constant load tests a single partial un-/reloading cycle was used during the chloride transient. For the applied PPU and the low-flow conditions in the autoclave, the dilution effects on the occluded crack crevice chemistry after a chloride transient in high-purity bulk water by convection due to the relative movement of the crack flanks is believed to be minimal. 


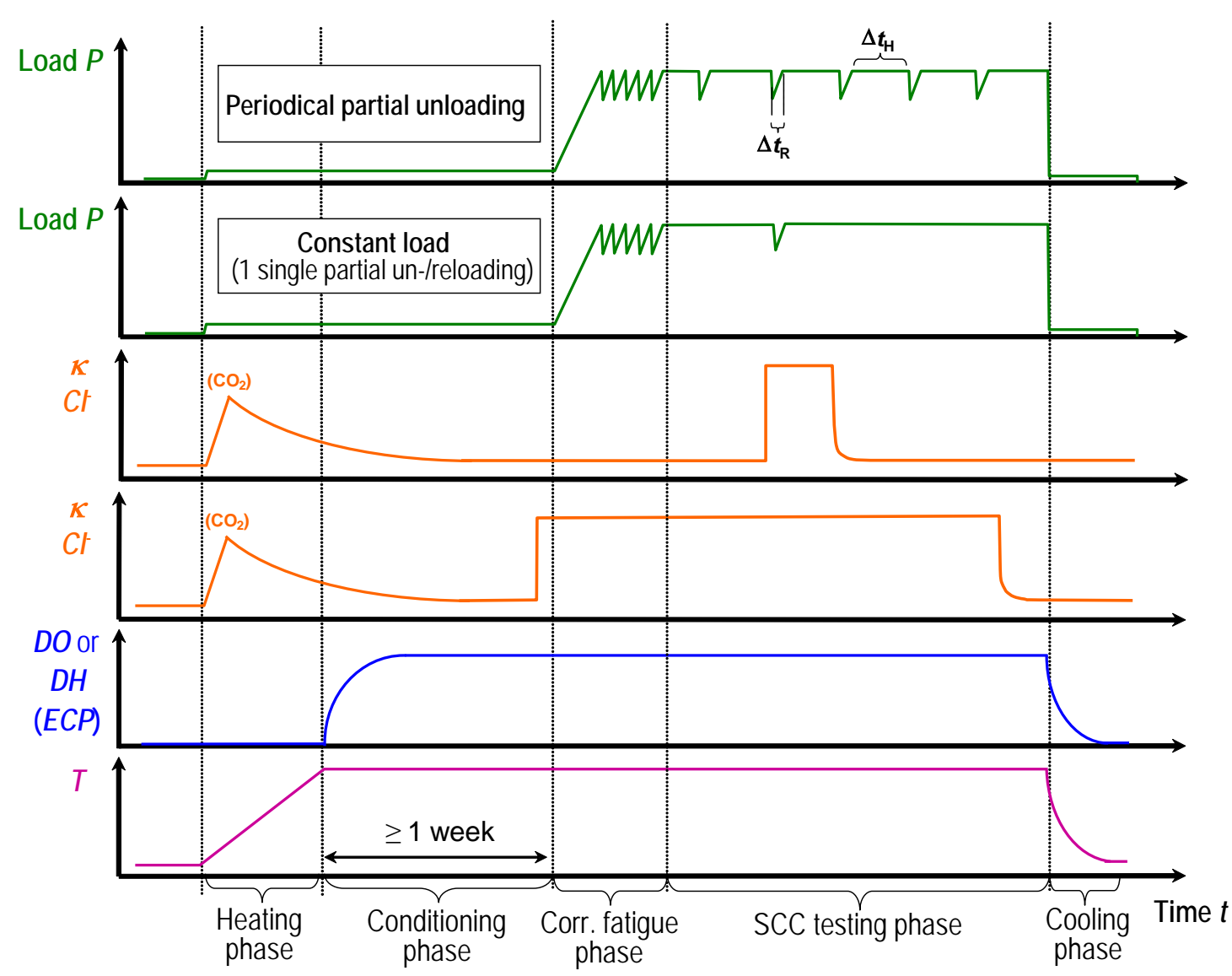

Figure 3: Simplified schematic of the applied test procedure for SCC experiments in high-purity hightemperature water with addition of chloride. (The conductivity peak in the heating phase is from residual $\mathrm{CO}_{2}$ of the initial air volume in the autoclave and impurities in the stagnant water in the piping during the filling and heating of the autoclave. They are completely removed by $\mathrm{N}_{2}$ purging and ion exchangers during the heating before the condition phase is started).

\section{Results and Discussion}

\subsection{NWC Environment}

Temporary chloride transients: In chloride transient tests in NWC environment, an acceleration of SCC crack growth may occur under constant load a few hours (up to at maximum a few ten hours) after chloride addition in case of an active growing SCC crack or the presence of sharp crack-tips due to the pervious cycling or slow rising loading shortly prior to the chloride addition (Figure 4). Otherwise, no accelerating effect of chloride on SCC was observed even after prolonged chloride exposures of several hundreds of hours under constant load (Figure 5). The latter one is the common observation in highpurity water at $K_{I}$-levels below $60 \mathrm{MPa} \cdot \mathrm{m}^{1 / 2}$ at 274 to $288{ }^{\circ} \mathrm{C}$, where no sustained SCC is usually observed [7].

Figures 4a and b show the EAC behaviour of the RPV steel E in a constant load test with PPU (to 70 \% of the maximum load every $12 \mathrm{~h}$ ) with an initial $K_{I}$ of $\sim 50 \mathrm{MPa} \cdot \mathrm{m}^{1 / 2}$ during a $50 \mathrm{ppb}$ chloride transient for 41 hours. In this experiment the chloride addition started briefly after an un-/reloading cycle. At that time, a relatively sharp crack with very slow local SCC crack growth (below the DCPD resolution limit 
of $5 \cdot 10^{-12} \mathrm{~m} / \mathrm{s}$ ) was still present. In the initial high-purity water, the crack was only growing by SICC during the rising load phase with no or only very minor SCC during the constant load phases of the PPU cycles, thus with the characteristic and usual behaviour [7]. $3 \mathrm{~h}$ after adding $\mathrm{NaCl}$ to the high-purity water, onset of fast EAC occurred during the constant load phase of a PPU cycle (see Figure $4 \mathrm{a}$ ). $17 \mathrm{~h}$ later, the EAC crack growth reached a stationary state during the rising $\left(\mathrm{d} a / \mathrm{d} t_{\mathrm{RL}}=1.4 \cdot 10^{-7} \mathrm{~m} / \mathrm{s}\right)$ and constant load $\left(\mathrm{d} a / \mathrm{d} t_{\mathrm{CL}}=1.8 \cdot 10^{-8} \mathrm{~m} / \mathrm{s}\right)$ part of the next PPU cycle with a mean CGR of $2.2 \cdot 10^{-8} \mathrm{~m} / \mathrm{s}$ (694 mm/year). The chloride resulted only in a very minor acceleration of SICC crack growth $(<2 \mathrm{x})$ in the rising load phase, but had a tremendous effect on the SCC crack growth in the constant load periods $\left(<5 \cdot 10^{-12} \mathrm{~m} / \mathrm{s} \rightarrow 1.8 \cdot 10^{-8} \mathrm{~m} / \mathrm{s}\right)$. After stopping the $\mathrm{NaCl}$ dosage, the crack was further growing with the same high CGR under constant load until the next partial unloading (Figure 4b). Then the crack growth started to slow down to a mean CGR in the same range as observed before the chloride transient. The slightly higher CGR was assigned to the higher $K_{I}$ values. The decay of the crack growth after the chloride transient might have been caused by (oxide- and surface roughness-induced) crack closure effects during the partial unloading [7]. Therefore, a possible long-term effect of a chloride transient on the EAC crack growth behaviour under constant load could not be fully excluded based on this specific experiment.

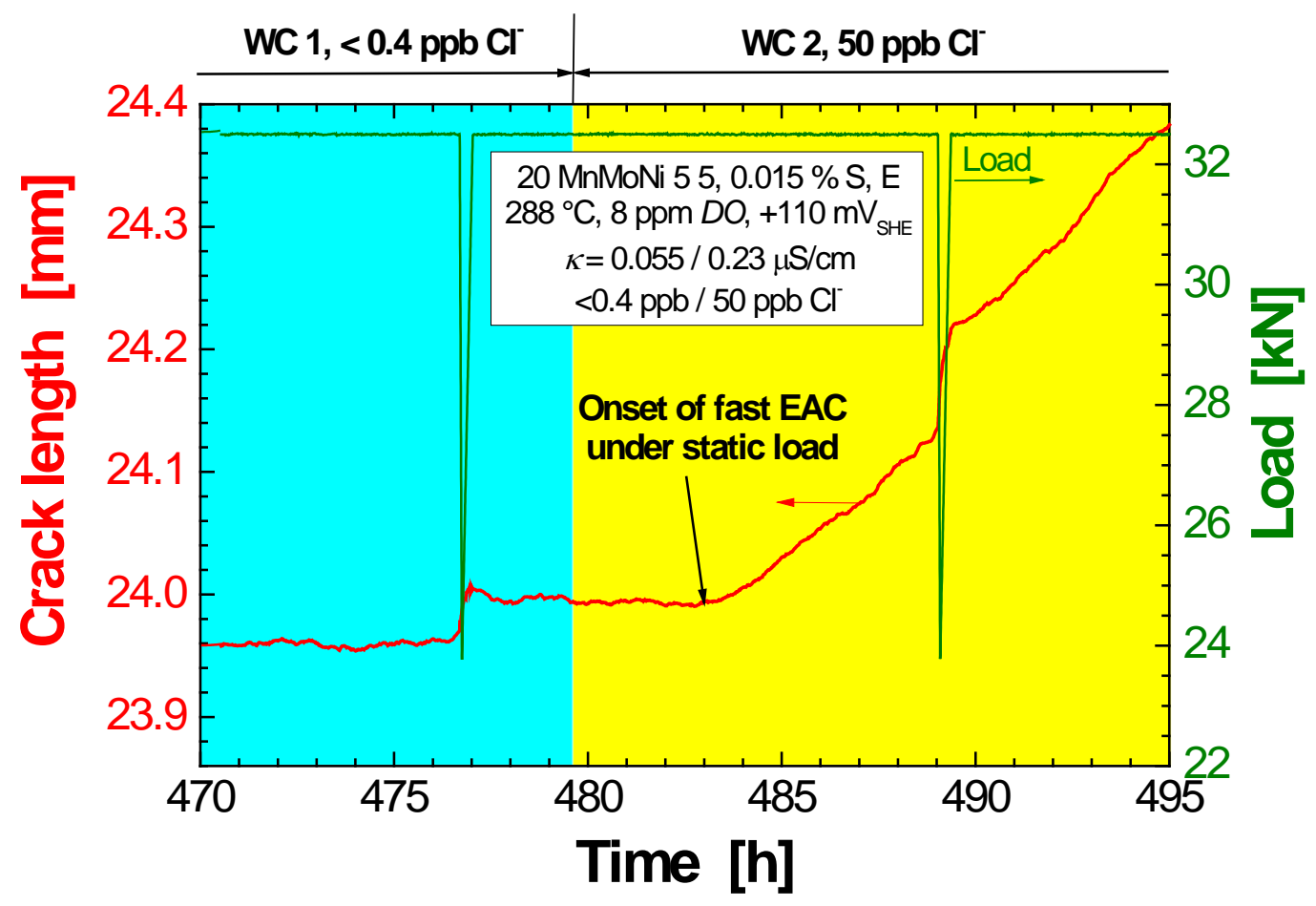

Figure 4a: Onset of accelerated SCC during constant load phase three hours after the addition of $50 \mathrm{ppb}$ of chloride to the oxygenated high-temperature water in a test with PPU. 


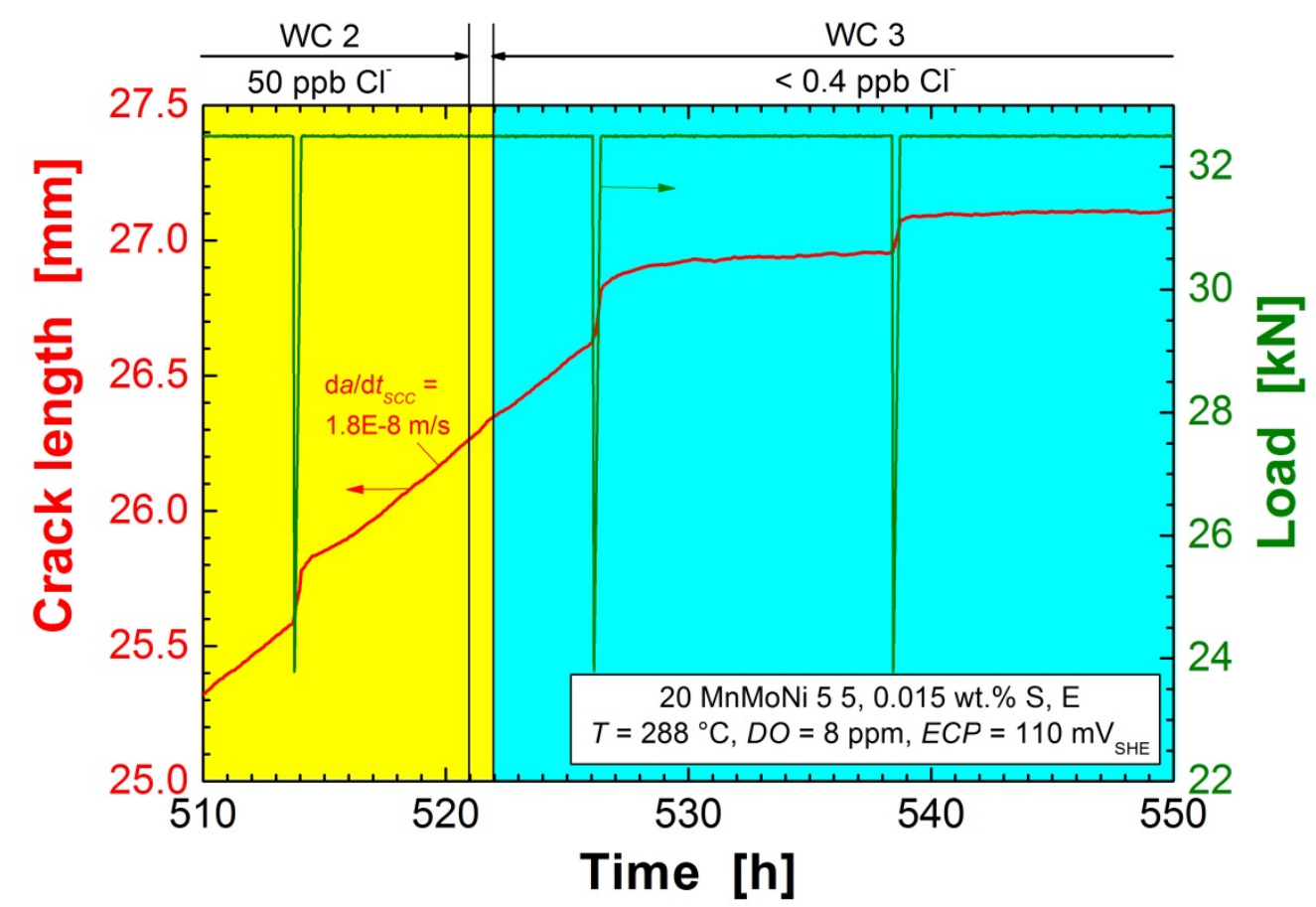

Figure 4b: Cessation of SCC crack growth after returning to high-purity water and an un-/reloading cycle.

A non-growing "dormant", blunted crack is the typical SCC situation for prolonged constant load exposure in high-purity water at $K_{I}$-levels below $60 \mathrm{MPa} \cdot \mathrm{m}^{1 / 2}$ at 274 to $288{ }^{\circ} \mathrm{C}$ [7]. For such cracks, in spite of the aggressive occluded crevice chemistry with chloride enrichment, no onset of fast SCC crack growth was observed under pure constant load in the $K_{I}$-range of 30 to $40 \mathrm{MPa} \cdot \mathrm{m}^{1 / 2}$ even after 10 days of chloride addition of $20 \mathrm{ppb}$. In contrast to high-purity or sulphate containing water, the onset of fast SCC could be stimulated by a single partial unloading/reloading cycle in these situations (Figures 5 and $6)$.

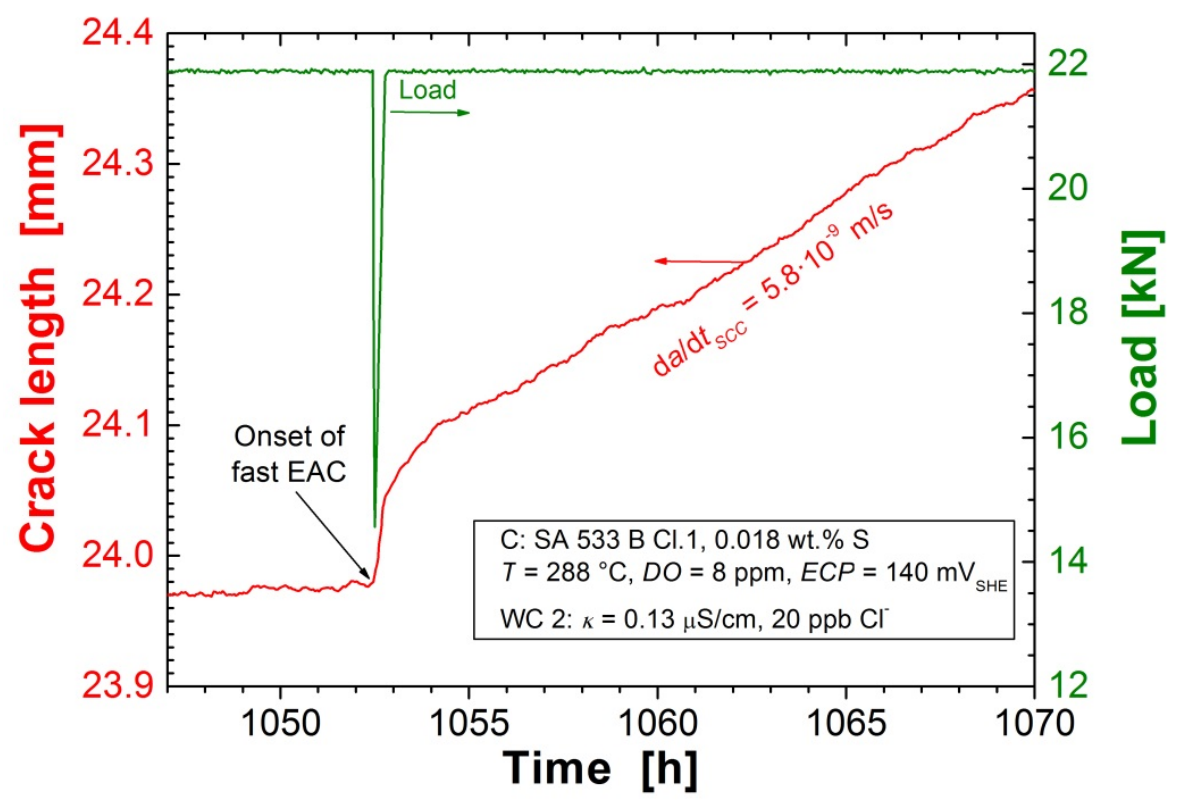

Figure 5: Onset of fast SCC during a chloride transient 10 days after the addition of $20 \mathrm{ppb}$ of chloride by a single partial un-/ reloading cycle. 
In Figure 6, the SCC crack growth behaviour in the RPV steel C under constant load in high-temperature water with $0.4 \mathrm{ppm} D O$ before, during and after a 4 day transient with $10 \mathrm{ppb}$ of chloride is shown. The onset of fast SCC occurred 24 hours after the chloride addition during the reloading phase of a partial un-/reloading cycle due to dynamic straining of the crack-tip. Sustained, stable SCC under pure constant load with a CGR value of $1.9 \cdot 10^{-9} \mathrm{~m} / \mathrm{s}(60 \mathrm{~mm} /$ year $)$ was observed. $1 \mathrm{~h}$ after returning to high-purity water the crack growth slowed down to a mean CGR of $5.9 \cdot 10^{-11} \mathrm{~m} / \mathrm{s}$ ( $2 \mathrm{~mm} /$ year) for further $174 \mathrm{~h}$ before continuous cessation of the crack growth occurred.

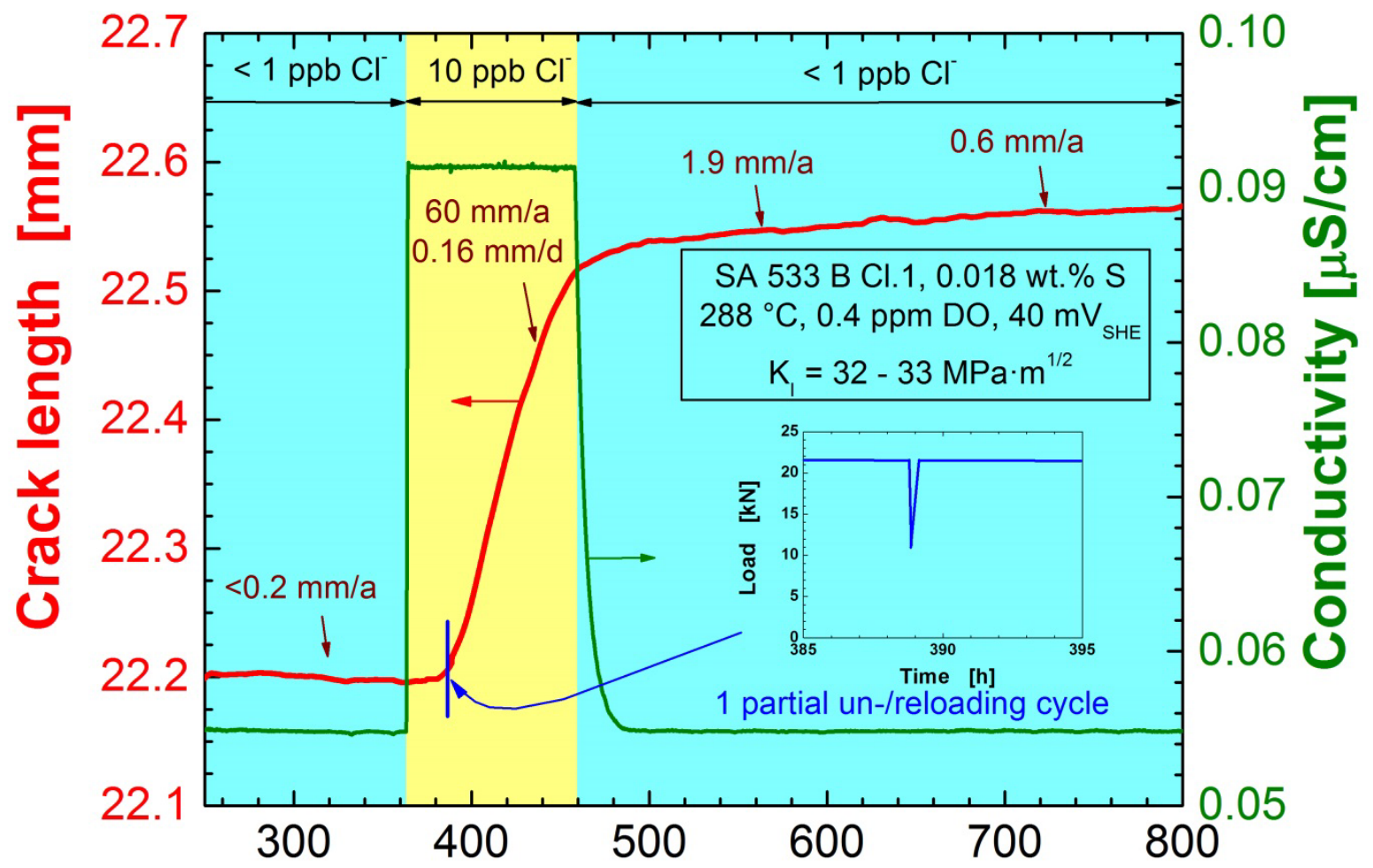

Figure 6: SCC crack growth before, during and after a 4 day chloride transient of $10 \mathrm{ppb}$ (added as $\mathrm{NaCl}$ ) under simulated BWR NWC conditions.

Chloride transients do not necessarily result in an acceleration of SCC crack growth under constant load, in particular in case of a "dormant" non-growing crack. The chemical blunting of the crack-tip by the accelerated corrosion in a strongly chloride-enriched crack crevice chemistry after long-term exposure might even be beneficial, if no localized film break-down occurs. Nevertheless, chloride may not be regarded as harmless species under these conditions. Slow localized SCC crack growth cannot be fully excluded in NWC environment [7] and active SCC crack growth towards the RPV steel is possible in dissimilar RPV attachment and penetration welds [4]. In a Swedish test program in the Oskarshamn 3 BWR, a large number of bolt-loaded pre-cracked C(T) specimens of different RPV steels has been exposed to NWC during a five-year period [25]. One of these specimens revealed significant SCC crack growth and there was some evidence that the overwhelming part of crack growth probably occurred during a 20 day chloride transient of 5 to $30 \mathrm{ppb}$, which happened during the third year of exposure because of a condenser leakage briefly after an outage. This clearly indicates the possibility of onset of accelerated SCC crack growth even in passively loaded pre-cracked specimens, although with a much lower probability/frequency. Furthermore, as shown by our tests, small additional dynamic straining (e.g. by small pressure or thermal fluctuations during plant operation) may be sufficient to cause fast and sustained SCC as long as a chloride enriched crack-crevice environment still prevails. 
After returning to high-purity water, the cracks usually were still growing with rather high CGRs for some 10 to $50 \mathrm{~h}$ before a decay of the crack propagation rate was observed. In case of moderate chloride transients $(\leq 10 \mathrm{ppb})$, the SCC CGRs then dropped again to the same low values as in high-purity water $(<0.6 \mathrm{~mm} /$ year) within some few further hundreds of hours (Figure 6). The situation was thus fully reversible for moderate, short-term transients. After severe ( $\geq 15 \mathrm{ppb}$ ) and prolonged ( $\geq 200 \mathrm{~h})$ chloride transients, sustained fast SCC crack growth was observed for at least $1000 \mathrm{~h}$ (Figures 7 and 8), before the tests were finished. Long-term effects thus cannot be excluded for such severe transients and they thus represent a serious concern.

Figure 7 shows, the SCC behaviour in the RPV steel C after a 291 h transient with 20 ppb of chloride. In this case, the crack was growing with the same rate for further $41 \mathrm{~h}$ (delay time) after returning to highpurity water. Then the crack growth slowed down to a mean CGR of $7.0 \cdot 10^{-10} \mathrm{~m} / \mathrm{s}$ (22 mm/year), which still was significantly higher than before the transient. The crack growth after the chloride transient consisted of periodic sequences of longer phases with slightly lower CGR (3 to $5 \cdot 10^{-10} \mathrm{~m} / \mathrm{s}$ ) and shorter phases with significantly faster transient CGR $\left(5 \cdot 10^{-9} \mathrm{~m} / \mathrm{s}\right)$ than the long-term mean value of $7.0 \cdot 10^{-10} \mathrm{~m} / \mathrm{s}$ (Figure 7). This special shape of crack growth was caused by local crack pinning (periods with slightly slower CGR) and sub-sequent retarded and stepwise failure of these uncracked ligaments (periods with higher transient CGR) by EAC or ductile tearing, which was further confirmed by post-test fractography. Similar shapes of crack growth versus time curves were observed in many other PSI tests with fast SCC under constant load [7]. Stable, fast SCC with CGR above the BWRVIP-60 SCC Disposition Line 2 could be sustained for more than $1000 \mathrm{~h}$ after returning to high-purity water in alloy $\mathrm{C}$. This showed that there might be a distinctive long-term effect after severe ( $\geq$ EPRI Action Level 2 ) and prolonged chloride transients (Figures 7 and 8).

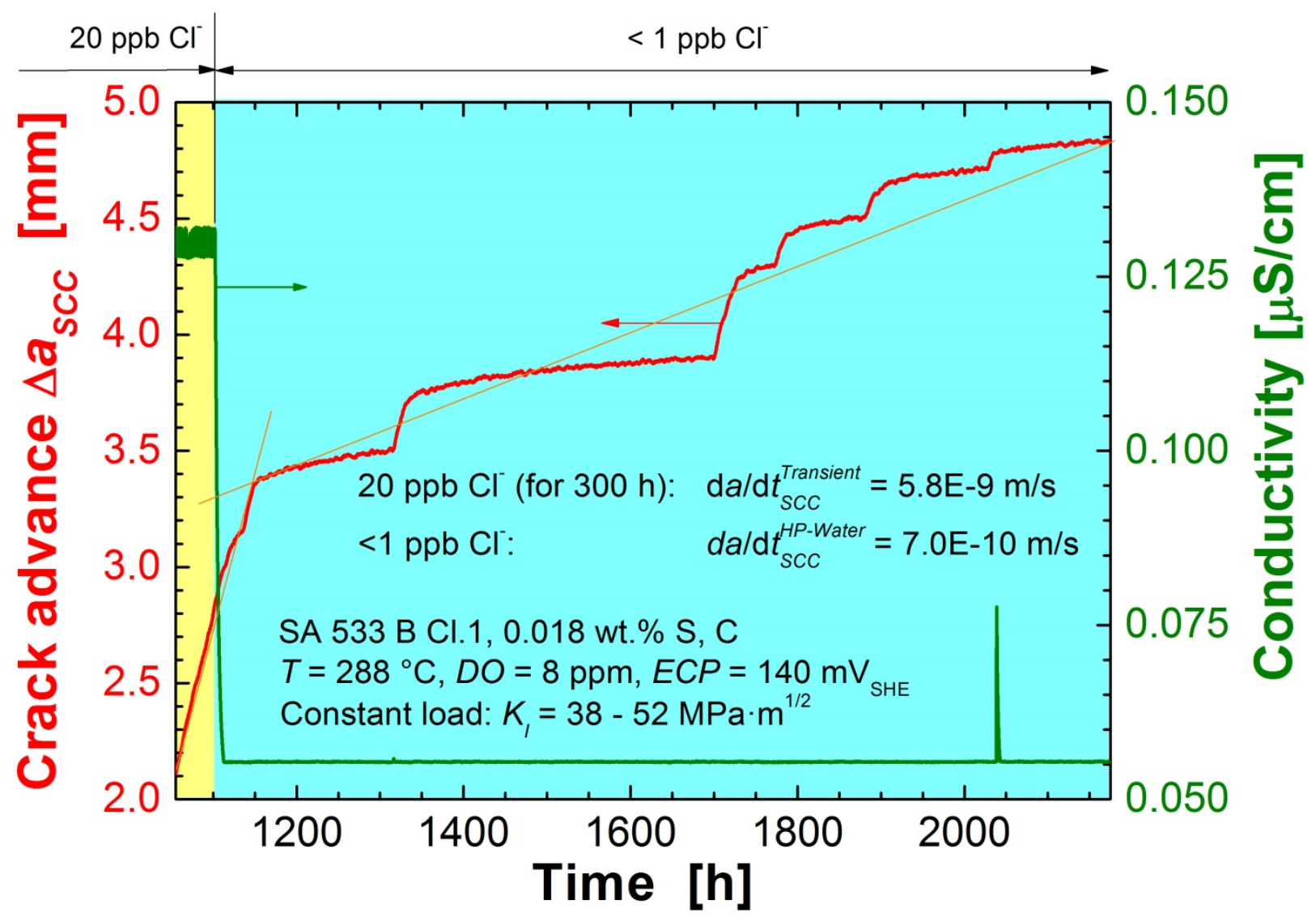

Figure 7: Example of sustained SCC with CGR above BWRVIP SCC Disposition Line 2 after a severe long-term chloride transient (20 ppb for 291 hours). 


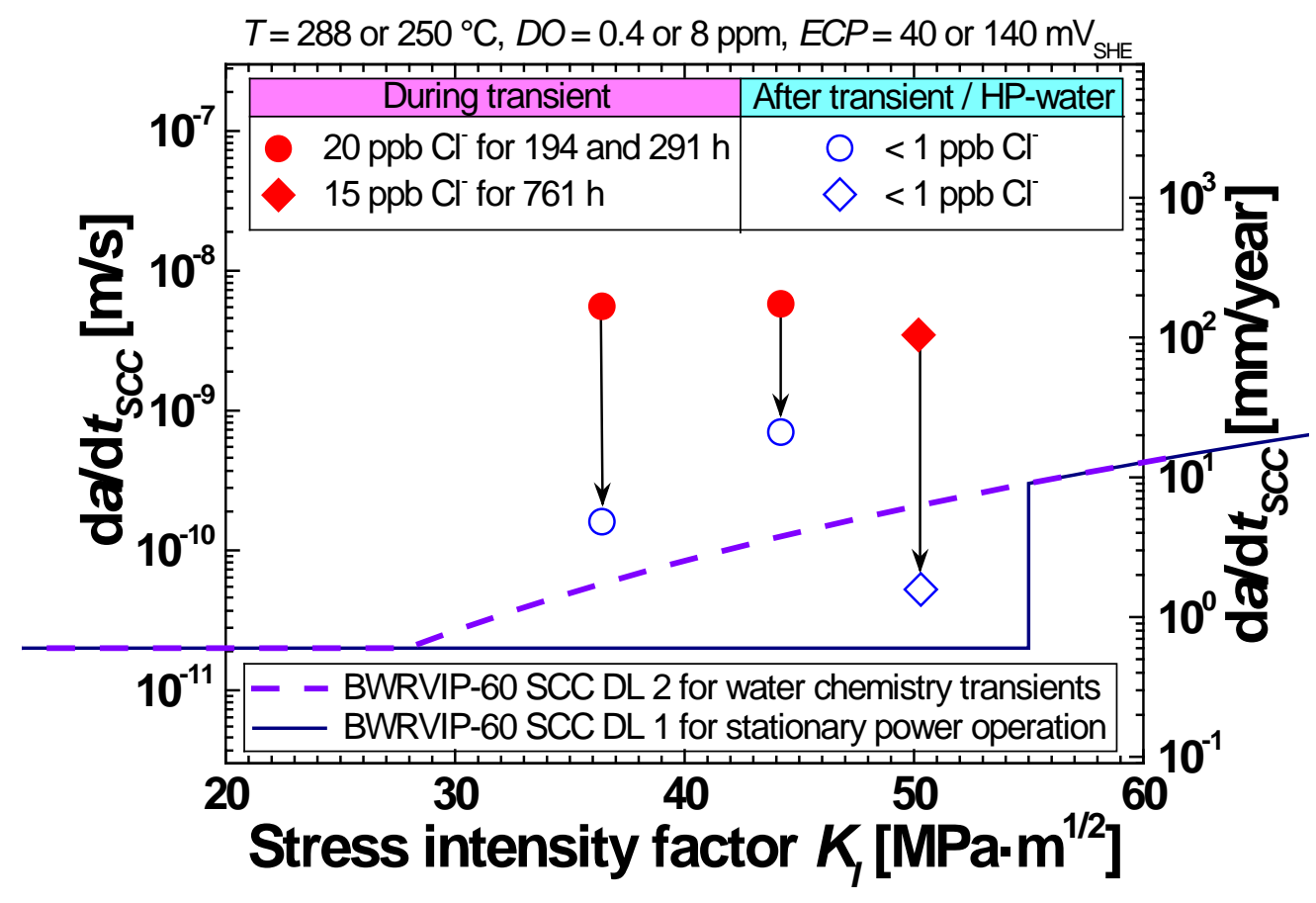

Figure 8: Test results with sustained stationary SCC in high-purity water during the whole remaining test period of up to $1200 \mathrm{~h}$ after severe $(\geq 15 \mathrm{ppb})$ and prolonged chloride excursions ( $\geq 200$ h).

The observed transient SCC behaviour is in line with crack crevice chemistry models [1, 2, 22]. The evolution of an occluded crack crevice chemistry with chloride or sulphate anion enrichment under oxidizing BWR/NWC conditions at $288{ }^{\circ} \mathrm{C}$ typically occurs within some few hours up to one day (depending on bulk chloride/sulphate content, ECP or potential gradient in the crack mouth region and crack length, etc.) [22]. The reasons for the significantly asymmetric hysteresis behaviour and different time constants for acceleration and decay of SCC crack growth during and after a chloride transient in NWC environment is primarily related to ion migration due to the potential gradient in the crack crevice and to the dependence of the crack crevice chemistry and crack-tip strain rate on crack growth rate and vice versa [1, 2]. After chloride addition, there is an additive concentration-gradient driven diffusion flux and potential-gradient driven migration flux of chloride towards the crack-tip resulting in a built-up of a chloride concentration gradient. Under stationary conditions, the migration flux towards the crack-tip and back-diffusion flux due to the concentration gradient are equal. After returning to a high-purity bulk environment, chloride diffuses out the crack, but the migration towards the crack-tip reduces the net flux. Particular long-term effects after severe chloride transients might be anticipated, if the chloride solubility limit is exceeded in the crevice environment during the transient resulting in chloride precipitation or if chloride is reversibly absorbed on/in the oxide film at the crack-tip and flanks. In both situations a large amount of chloride can be pumped into the crack during severe long-term transients and a huge chloride reservoir would be available after returning to high-purity water. There is no experimental direct evidence for both cases so far.

Similar observations on the effect of chloride transients with the RPV steel D $(0.007 \%$ S, low DSA susceptibility, lowest EAC susceptibility in PSI investigations) were obtained by M. Herbst et al. [26, 27] and Herter et al. [28] in a very limited number of tests at slightly lower ECPs. In case of dormant cracks under pure constant load, no acceleration of SCC was observed even for prolonged and severe chloride transients of $50 \mathrm{ppb}[27,28]$ and up to $150 \mathrm{ppb}$ [28]. A single partial un-/reloading cycle 
immediately induced fast SCC during chloride transients with similar CGRs as in the PSI investigations. After returning to high-purity water, the SCC CGRs quickly declined, but were then further growing with a slow SCC rate in several cases. In case of a sharp and very slowly growing crack under pure constant load, acceleration of SCC already occurred 3 hours after the addition of $50 \mathrm{ppb}$ of chloride [27]. On the other hand, $100 \mathrm{~h}$ after a $100 \mathrm{~h}$ chloride transient of $50 \mathrm{ppb}$ in case of a dormant crack, three partial un\& re-loading cycles did not induce accelerated SCC crack growth [28], indicating that the original crack crevice chemistry already had re-established at this time, as expected. It is stressed that RPV steel D showed the lowest EAC susceptibility in PSI investigations in comparison to the other tested materials. Establishing fast EAC in this material, e.g. fast corrosion fatigue, was more challenging and occurred less frequently and required sometimes some additional stimulation. The focus in the PSI investigations was more placed on the high-sulphur RPV steels C and E. Together with the higher ECP and higher number of tests, this may explain the more pronounced effects at low chloride concentrations or the lower chloride thresholds at PSI.

Continuous chloride addition: In Figure 9, SCC CGRs under BWR NWC conditions during chloride additions between 5 and 50 ppb are summarized and compared to the EPRI Action Level limits 1 and 3. These results indicate a critical chloride concentration for the onset of fast SCC crack growth in the investigated LASs of 5 to $10 \mathrm{ppb}$ in the stress intensity factor range of 30 to $40 \mathrm{MPa} \cdot \mathrm{m}^{1 / 2}$. This range of critical chloride concentration is slightly above EPRI Action level limit 1.

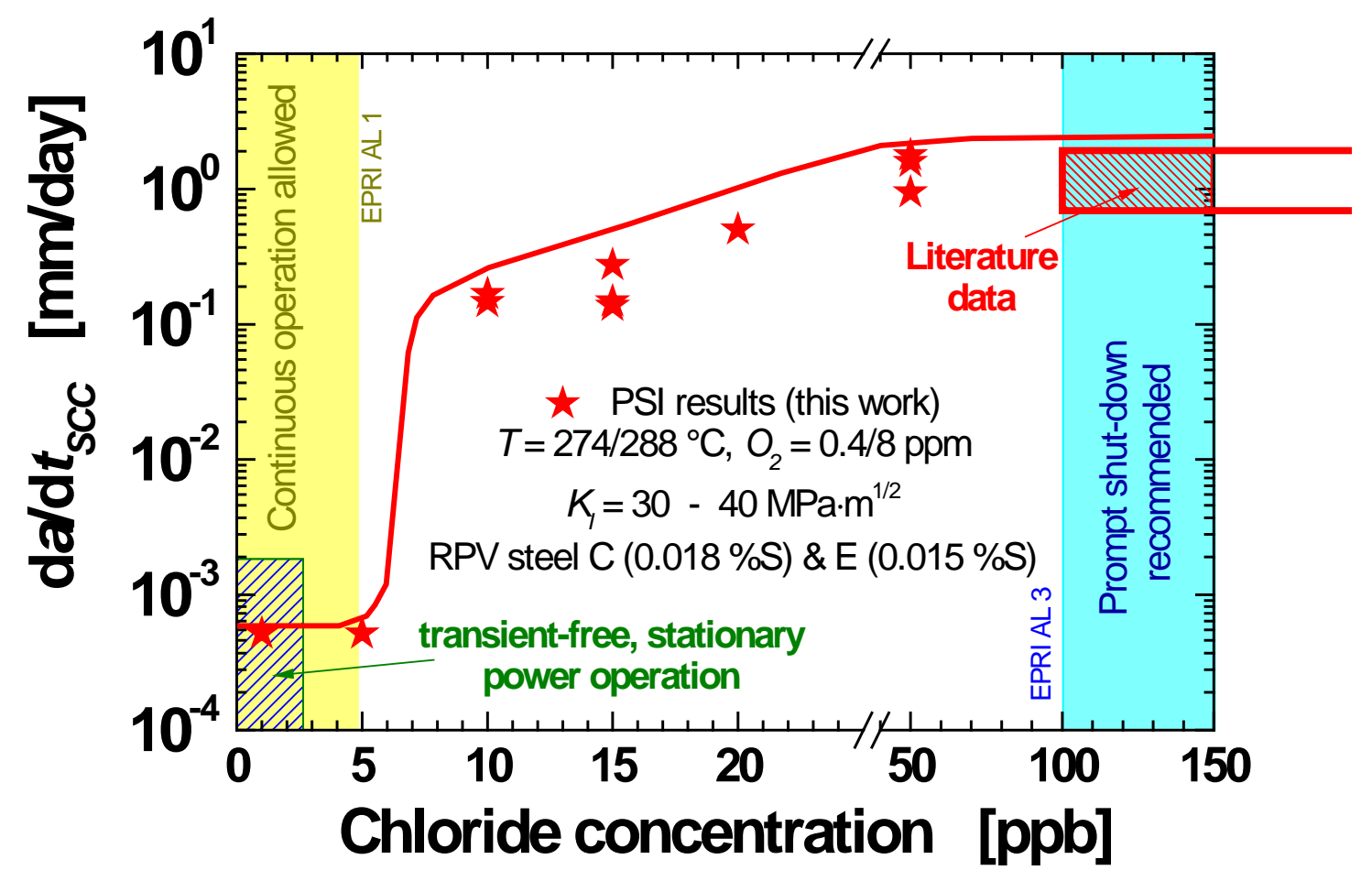

Figure 9: Effect of chloride concentration on SCC CGR in high-sulphur RPV steels (0.015 and 0.018 wt.\% S) under highly oxidizing BWR NWC conditions (ECP $=+50$ to $150 \mathrm{mV} \mathrm{SHE}_{\text {) }}$ and comparison with Action Level 1 and 3 range of the EPRI Water Chemistry Guidelines. [7]

All SCC crack growth data measured under oxidizing BWR NWC conditions with chloride impurities are compared to the BWRVIP-60 SCC Disposition Lines in Figure 10. It can be seen that very small amounts of chloride impurities in the range of 3 to $15 \mathrm{ppb}$ were already sufficient to induce fast SCC 
crack growth in the investigated LASs well above the BWRVIP-60 SCC Disposition Line 2 down to very low stress intensity factors of $20 \mathrm{MPa} \cdot \mathrm{m}^{1 / 2}$ for $\geq 10 \mathrm{ppb}$ of chloride. Therefore, Disposition Line 2 is not conservative for chloride containing ( $\geq 3 \mathrm{ppb}$ ) BWR NWC environment. The "high-sulphur crack growth curve" of the Ford \& Andresen model [12], on the other hand, acts as an upper bound for all crack growth data (Fig. 10). In former PSI SCC tests without chloride addition with an external Ag/AgCl reference electrode for ECP measurements, the low leakage flow of chloride from the $\mathrm{KCl}$ electrolyte bridge into the autoclave usually resulted in measured but variable chloride contents in the outlet water in the range of 1 to $3 \mathrm{ppb}$. No SCC was observed in these tests, suggesting that these extremely low chloride contents do not affect the SCC cracking behaviour.

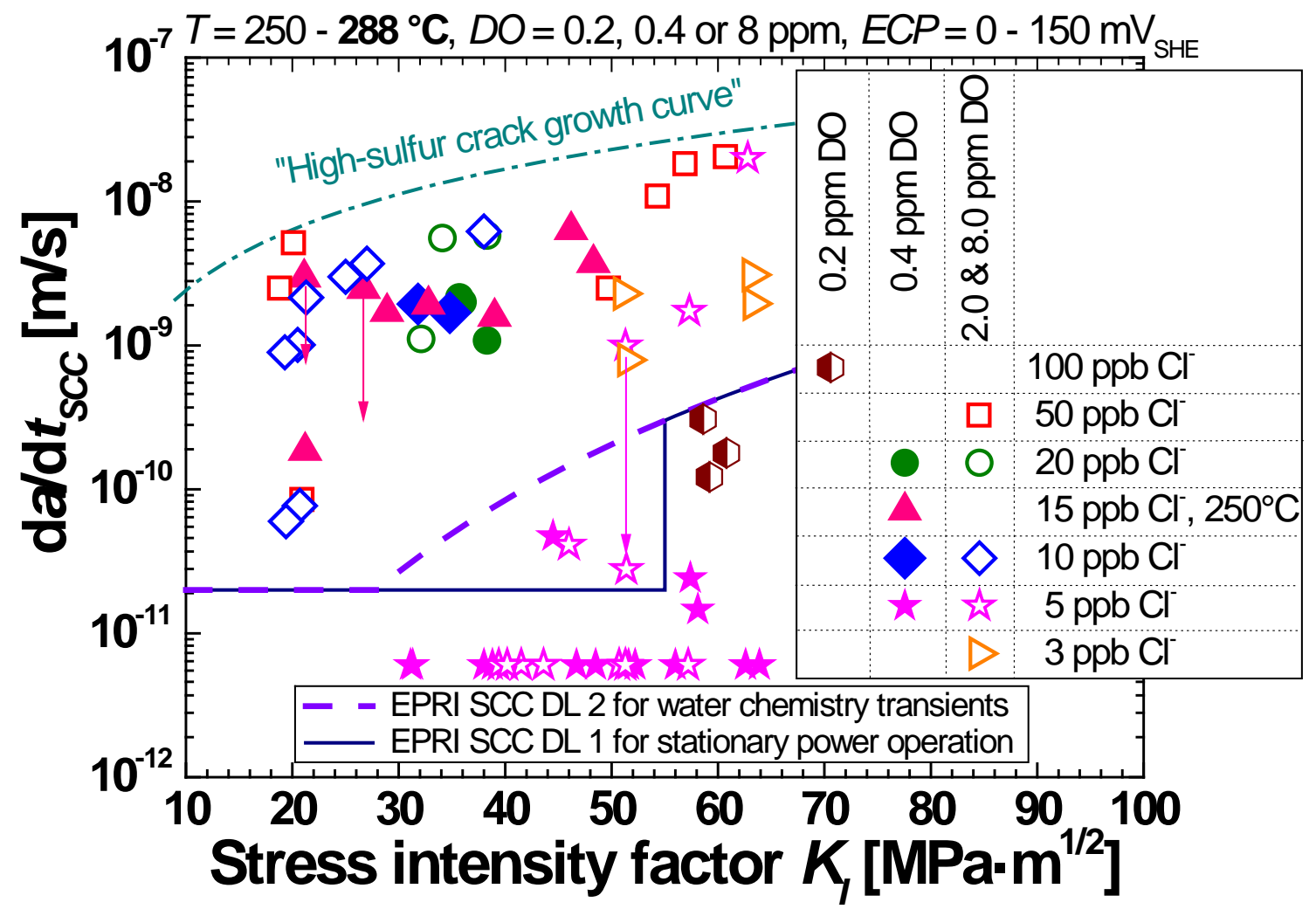

Figure 10: Comparison of SCC CGRs during chloride transients under BWR NWC conditions with the corresponding BWRVIP-60 SCC Disposition Lines 2 and 1 for water chemistry transients and stationary power operation.

As shown in Figure 11 for NWC environment, the chloride seems to shift the transition from very low $(\sim 0.5 \mathrm{~mm} / \mathrm{a})$ to high SCC growth rates $(>10 \mathrm{~mm} / \mathrm{a})$ in the range of the high-sulphur line of the Ford $\&$ Andresen model [12] from 60 to $70 \mathrm{MPa} \cdot \mathrm{m}^{1 / 2}$ in high-purity water to $20 \mathrm{MPa} \cdot \mathrm{m}^{1 / 2}$ at chloride levels $>5 \mathrm{ppb}$. It is believed that this transition is additionally affected by the steel sulphur content, DSA susceptibility, yield stress level or ECP in a synergistic manner with the chloride content. 


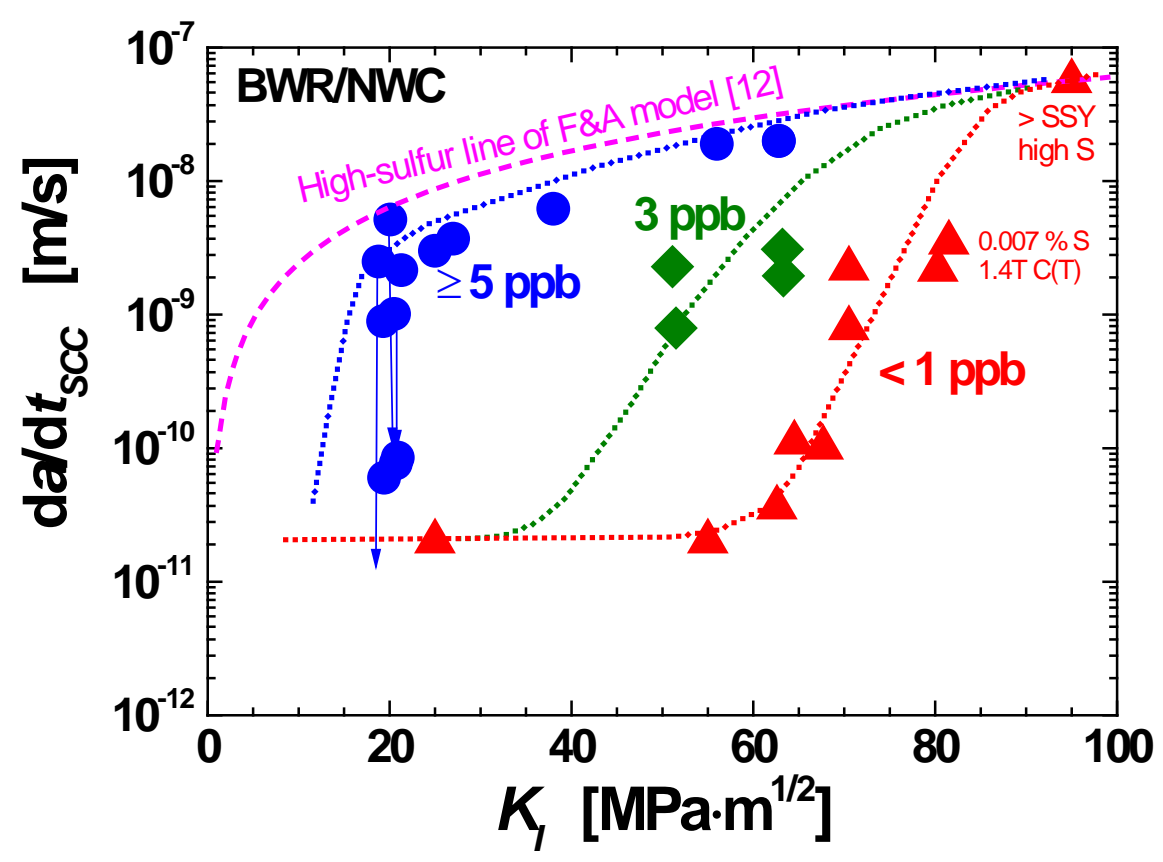

Figure 11: Transition from very slow to fast high-sulphur SCC CGRs in low-alloy RPV steels in BWR NWC environment as a function of chloride concentration [4]. Down pointing arrows indicate a continuous decay of SCC crack growth with SCC cessation tendency. (SSY = small scale yielding).

At $K_{I}$-levels below $\sim 20 \mathrm{MPa} \cdot \mathrm{m}^{1 / 2}$, an increasing tendency for cessation of SCC crack growth was observed even in high-sulphur RPV steels at high chloride levels of $50 \mathrm{ppb}$ as exemplarily shown in Figure 12, eventually indicating the beginning of a kind of threshold behaviour. The initially high SCC CGRs could not be sustained and usually dropped down by a factor of 5 to 10 with crack arrest in some cases.

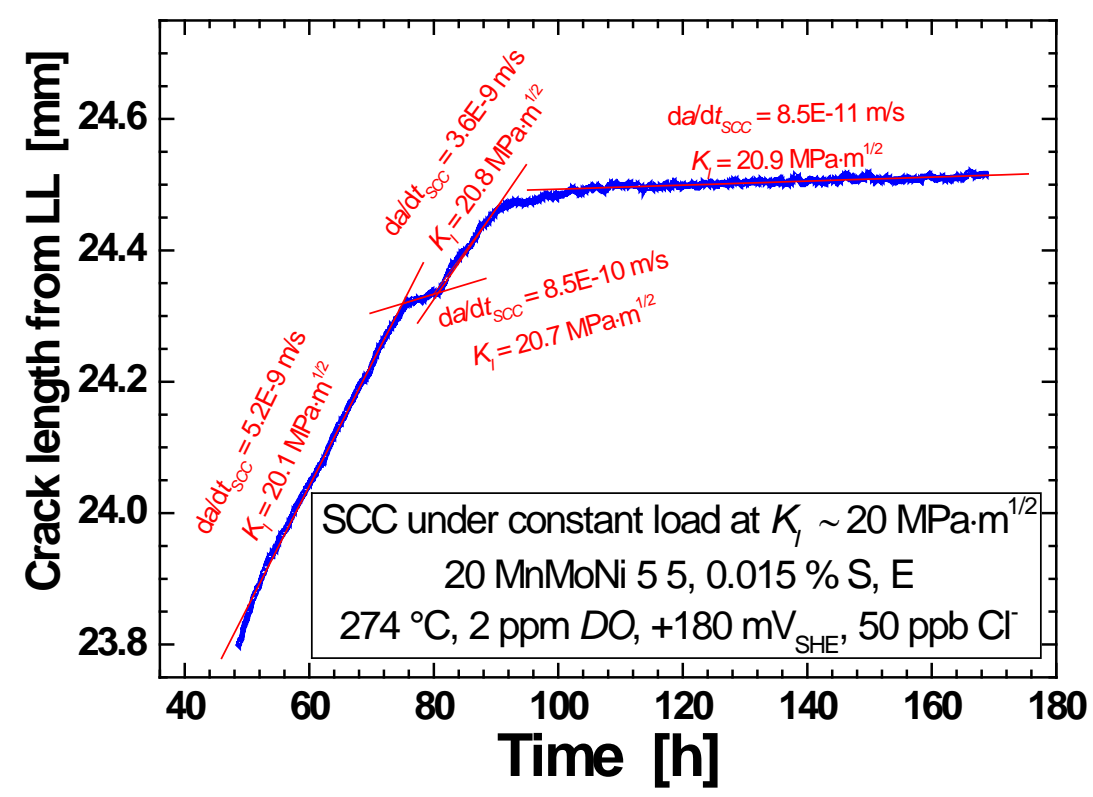

Figure 12: Example of observed SCC cessation behaviour at a $K_{I}$-level below $\sim 20 \mathrm{MPa} \cdot \mathrm{m}^{1 / 2}$. 
The observed behaviour was also confirmed by the DMW specimens, where SCC crack growth through the fusion boundary and fast SCC in the RPV base metal was observed at least down to stress intensity factors of 50, 30 and $20 \mathrm{MPa} \cdot \mathrm{m}^{1 / 2}$ for chloride contents of 3, 5 and $10 \mathrm{ppb}$, respectively [4]. Figure 13 shows the critical combinations of $K_{I}$ at the fusion line and added chloride concentration for SCC crack growth into the LAS under highly oxidizing BWR NWC conditions. The critical chloride content or $K_{I^{-}}$ levels thereby decreased with increasing $K_{I}$ or chloride content, respectively. These observations were confirmed by similar SCC investigations of comparable DMWs at General Electric Global Research in chloride containing water [29, 30].

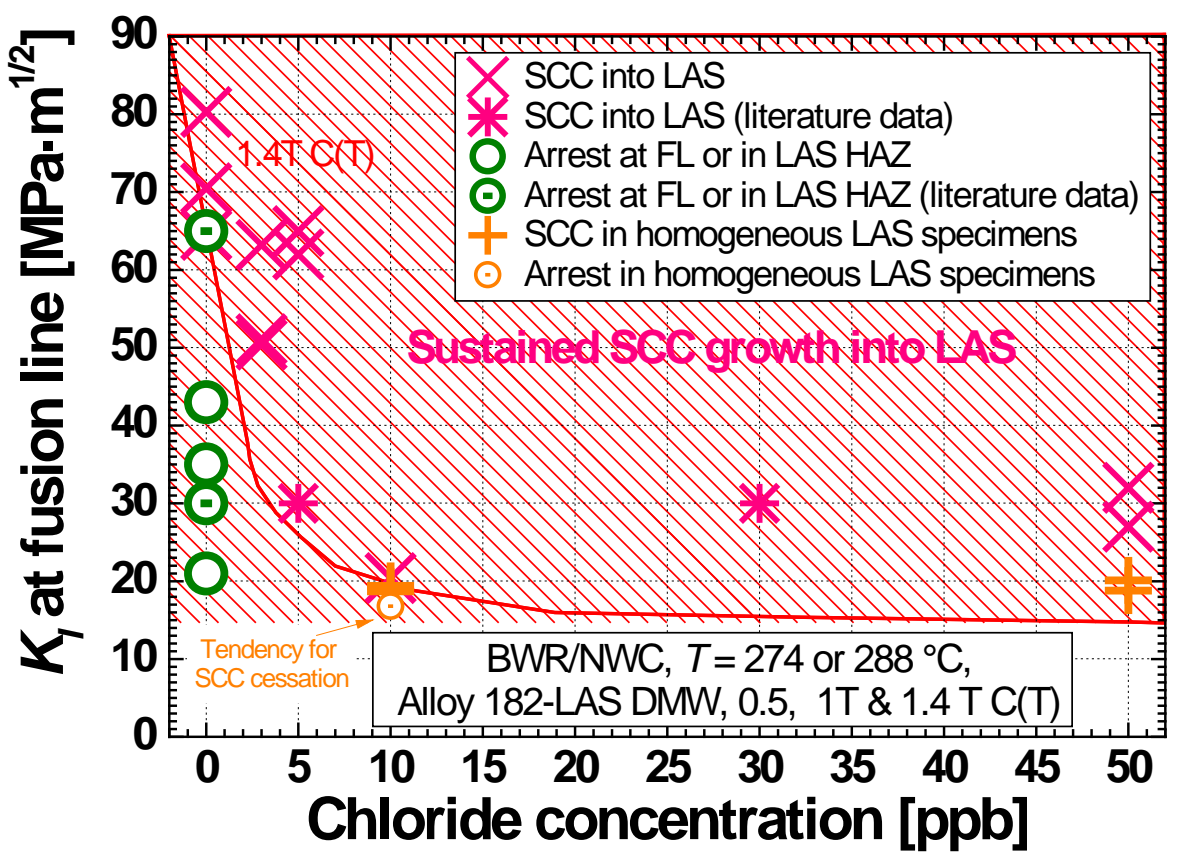

Figure 13: Critical combinations of $K_{I}$ and chloride concentration for SCC crack growth into the LAS under BWR/NWC conditions (FL = fusion line). Additional data from the literature [29] is included.

Material aspects: All the tested RPV steels revealed the same behaviour in case of chloride additions, and neither the sulphur content (0.004 to 0.018 wt.\% S) nor the orientation (TS, ST, TL) or the DSA susceptibility of the RPV steel had a significant effect in the investigated parameter range (this is not to say that these parameters cannot affect the cracking behaviour, in fact they are synergistic with the chloride effects). The simultaneously tested low- and high-sulphur RPV steels A (0.004 \% S) and C $(0.018 \%$ S) revealed similar local maximum SCC CGRs in high-temperature water with 2 ppm DO and $3 \mathrm{ppb}$ of chloride (Figure 14). The SCC crack growth in the low-sulphur RPV steel tended to be more uneven over the specimen thickness than in high-sulphur materials in some cases, in particular, at low chloride and low $K_{I}$ levels. In high-sulphur steels in high-purity water, there is a higher probability for some local SCC crack growth around MnS-inclusions that are intersected by the crack front, and thus a better chance for the onset or faster onset of accelerated SCC. In fact, in the medium-sulphur RPV steel D with a relatively low EAC susceptibility, onset of acceleration of SCC crack growth occurred $32 \mathrm{~h}$ after the addition of $50 \mathrm{ppb}$ in comparison to the $3 \mathrm{~h}$ in the simultaneously tested high-sulphur steel $\mathrm{E}$ in Figure 4. The corresponding SCC crack growth also was more uneven in the RPV steel D specimen. 


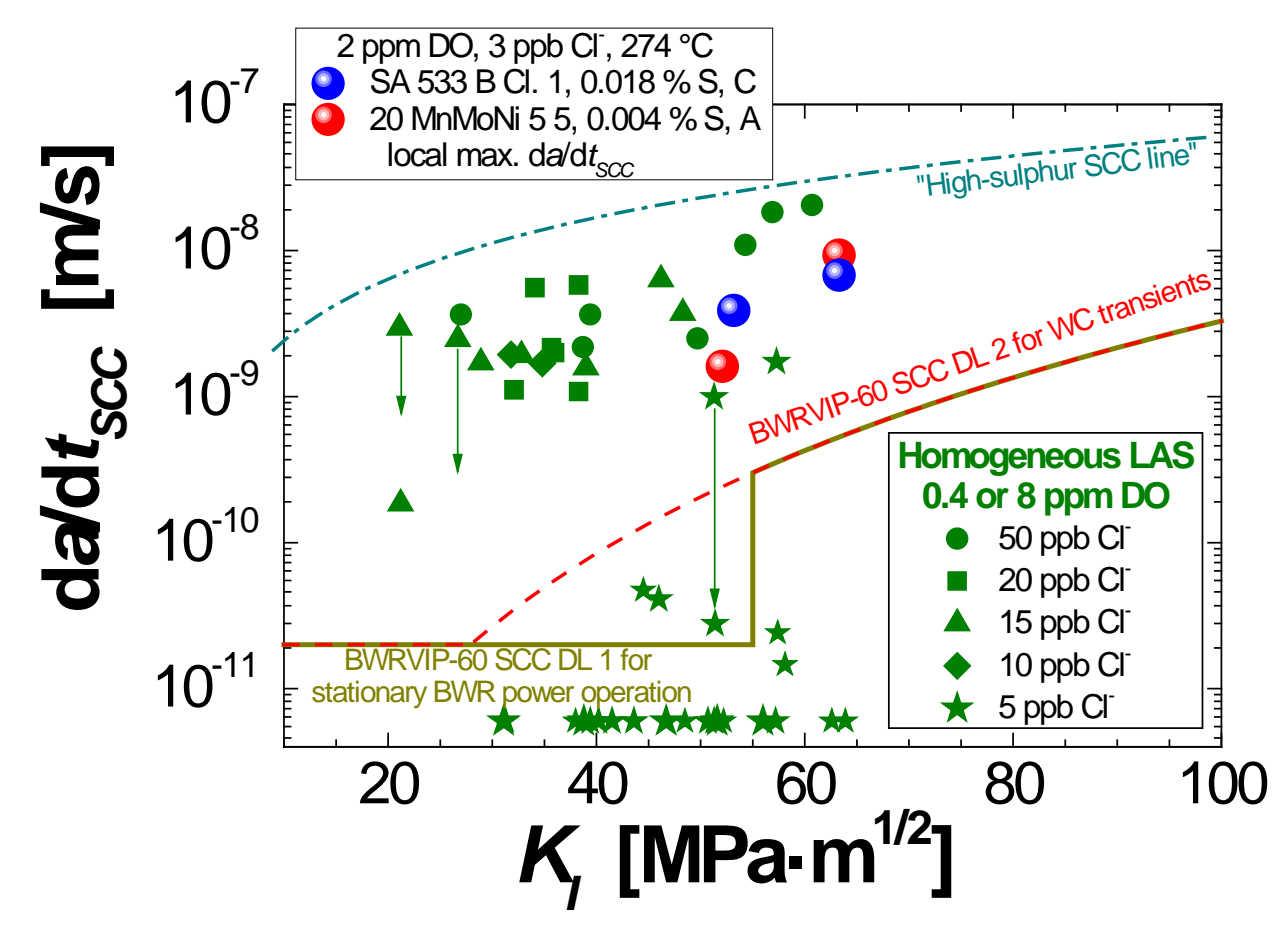

Figure 14: Comparison of local maximum SCC CGRs in a high- and low-sulphur RPV steel at 3 ppb of chloride with other RPV steel results.

SCC is possible in chloride-free NWC environment under certain circumstances, e.g., at high $K_{I}$-values $>\sim 70 \mathrm{MPa} \cdot \mathrm{m}^{1 / 2}$ (Figure 11), in RPV steels with high DSA susceptibility at intermediate temperatures (180 to $270{ }^{\circ} \mathrm{C}$ ) or in RPV weld HAZ with high hardness $\geq \sim 350 \mathrm{HV}$ (Figure 15). In these cases, chloride addition only results in a small SCC acceleration due to the much higher initial SCC growth rates. This is consistent with the observations that chloride has little effect on corrosion fatigue and SICC crack growth in NWC environment [1, 2, 19, 20].

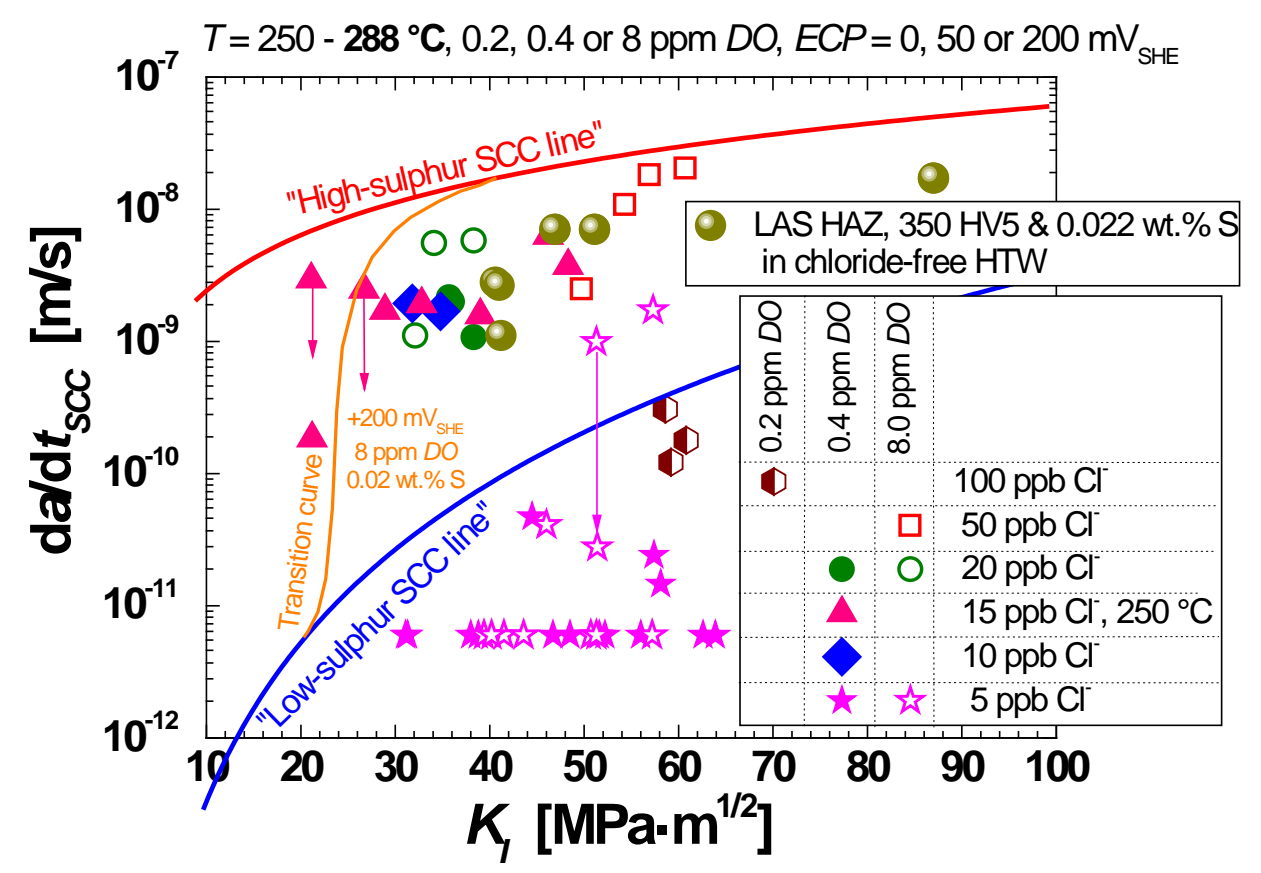

Figure 15: Similar SCC CGRs in susceptible RPV weld HAZ material in high-purity water as in other RPV steels in chloride containing water. 


\subsection{HWC Environment}

In some tests with fast SCC crack growth in chloride containing oxygenated BWR NWC environment, the $D O$ was removed and $150 \mathrm{ppb} D H$ added (simulated BWR HWC conditions). Soon after the ECP was reduced to about $-550 \mathrm{mV}$ SHE, the CGRs slowed down to values in the range of or even clearly below the BWRVIP-60 SCC Disposition Line 1 (Figure 16).

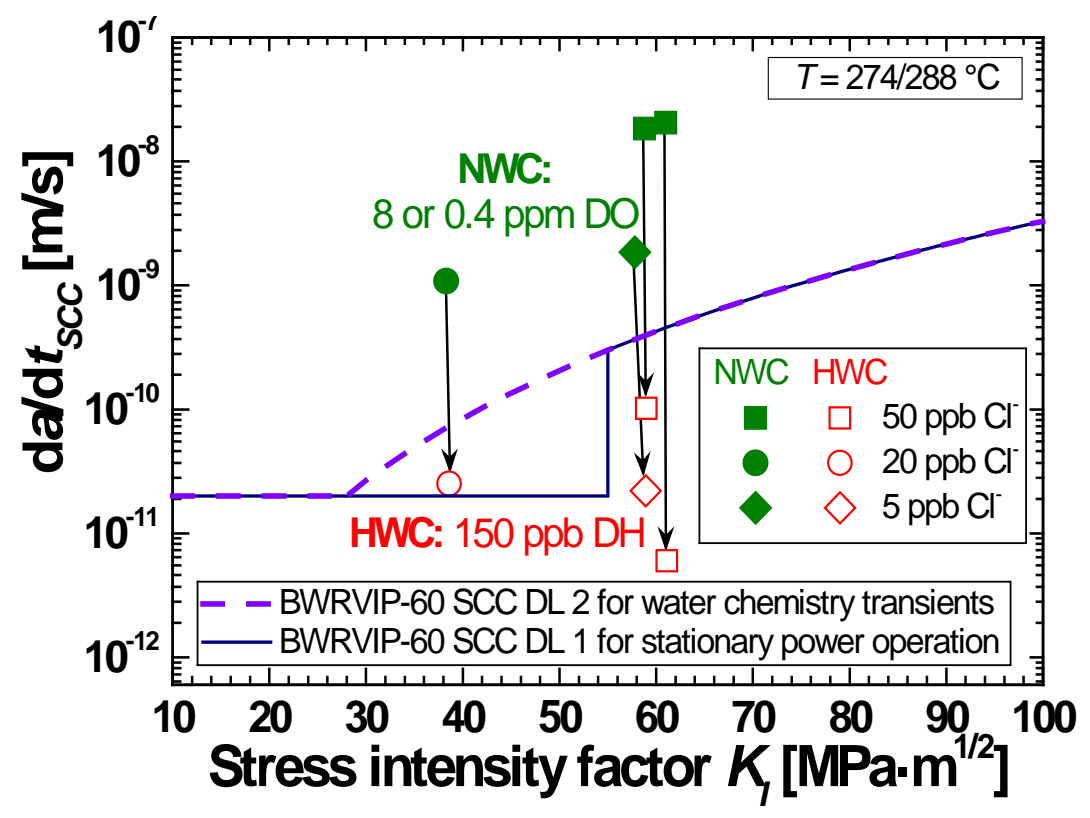

Figure 16: Effect of $D H$ addition and ECP reduction on the SCC crack growth during chloride transients and comparison to the BWRVIP-60 SCC Disposition Lines.

Figure 17 shows the combinations of ECP and chloride concentration that caused fast SCC crack growth. The critical chloride concentration for the onset of accelerated SCC strongly increased with decreasing ECP. Below $60 \mathrm{MPa} \cdot \mathrm{m}^{1 / 2}$, even $100 \mathrm{ppb}$ of chloride were not sufficient to induce fast SCC in LAS at an $E C P$ of $\leq-100 \mathrm{mV}_{\text {SHE }}$. These results thus indicate a significantly higher impurity tolerance at lower ECPs (e.g., in the feedwater piping system or under HWC conditions). The critical ECP for accelerated SCC, on the other hand, strongly increased with decreasing chloride concentration. This can be explained by the much lower chloride concentration in the crack-tip electrolyte in BWR HWC environment compared to BWR NWC conditions, following the basic concepts of crack electrochemistry for EAC under hightemperature water conditions [2, 22] as discussed in Section 3.4 under "Chloride effects". 


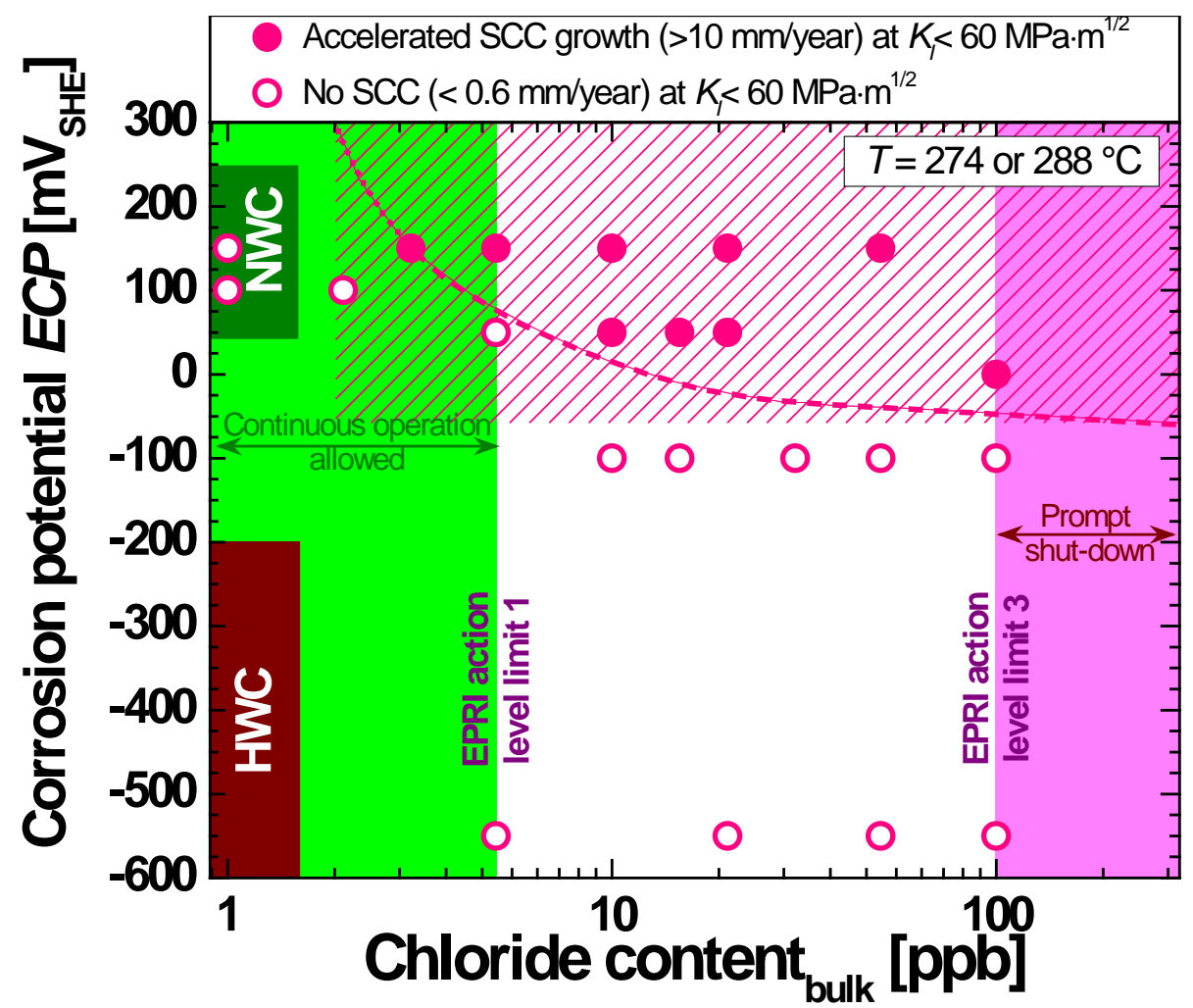

Figure 17: Synergistic effect of ECP and chloride content on the onset of fast SCC crack growth in LASs under BWR conditions and comparison with the typical conditions (NWC and HWC) during stationary power operation (increasing chloride tolerance with decreasing ECP).

\subsection{Assessment of BWRVIP-60 SCC Disposition Lines and EPRI Water Chemistry Guidelines}

In the following paragraphs, the adequacy and conservative character of the BWRVP-60 SCC Disposition Line 2 [11] for SCC crack growth in LAS during and $100 \mathrm{~h}$ after water chemistry transients (Figure 1) and of the EPRI BWR Water Chemistry Guidelines (Table 1) [13] are evaluated and assessed in the context of the recent test results and literature data presented in the previous sections.

The critical chloride content for the onset of fast SCC in RPV steels in NWC environment is in the range of 3 to $10 \mathrm{ppb}$ (depending on ECP, sulphur content, $K_{I}, \ldots$ ). The chloride thresholds for fast SCC are strongly increasing with decreasing ECP. At an ECP of -100 mV SHE (e.g., in the feedwater system) and under HWC conditions, $100 \mathrm{ppb}$ of chloride were not sufficient to induce fast SCC even in case of load transients and the situation with regard to chloride is thus quite relaxed here. The discussion is thus focused to NWC conditions in the following:

Summary of SCC behaviour during and after chloride transients: For growing sharp EAC cracks, short incubation periods of a few hours for acceleration of fast SCC are possible. On the other hand, in case of non-growing blunted cracks, even severe and prolonged chloride transients did not induce fast SCC under static load without load transients. During chloride transients $\geq 3 \mathrm{ppb}$, high SCC CGRs close to the highsulphur SCC line of the Ford \& Andresen model well above the BWRVIP-60 SCC Disposition Line 2 for water chemistry transients are observed. After moderate $(\leq 10 \mathrm{ppb})$ and short-term $(\leq 100 \mathrm{~h})$ chloride transients the SCC CGRs drop below $0.5 \mathrm{~mm}$ /year within few 10 hours to few 100 hours after returning to high-purity water and cessation of SCC crack growth generally occurs. After severe ( $\geq 15 \mathrm{ppb})$ and prolonged chloride transients ( $\geq 200$ h), stationary SCC with CGR above the BWRVIP-60 Disposition 
Line 2 could be maintained for much longer periods ( $>1000 \mathrm{~h}$ ) than the $100 \mathrm{~h}$ interval suggested by BWRVIP-60 and the CGR remained well above the BWRVIP-60 Disposition Line 1 for stationary, transient-free BWR power operation in several cases. A few ten hours after chloride transients, the original crack crevice is re-established (if crack growth is absent) and subsequent load transients do not induce accelerated SCC.

Potential impact of chloride transients on RPV integrity: The evolution of an occluded crack crevice chemistry with chloride-enrichment under oxidizing BWR NWC conditions at $288{ }^{\circ} \mathrm{C}$ typically occurs within some few hours up to at maximum some few 10 hours (depending on bulk chloride content, ECP and crack length, etc.) [22]. The original crack crevice chemistry is re-established within a few ten to some few hundred hours after the transient. Therefore, chloride-enriched crack crevice chemistry might be achieved in incipient cracks and crevices during typical plant water chemistry transients (ion exchanger resin intrusion, condenser leakage, etc.) and the presence of such cracks cannot be fully excluded (non-destructive testing resolution and detection limits, Alloy 182 attachment and penetration welds, locations with limited non-destructive testing access, etc.). According to the EPRI Water Chemistry Guidelines (Table 1) and depending on the Action Level, a water chemistry period of $24 \mathrm{~h}$ (limit 2) to $96 \mathrm{~h}$ (limit 1) would be allowed before returning to normal operation values. Because of the (potentially) very small incubation periods of less than a few hours, relevant acceleration of SCC crack growth may occur, if EPRI Action Level 1 is exceeded and a significant SCC crack advance of 0.5 to $2 \mathrm{~mm}$ may occur during transients of one to four days in extreme cases. As long as the number of transients is kept very low, this does not represent an RPV integrity concern. The potential long-term effects after severe and ( $\geq$ Action Level limit 2) and prolonged chloride transient represent a more serious integrity concern. If the observed SCC rates after such severe transients could be sustained for long periods, significant crack advances in the cm/year range could be achieved. Such potential long-term effects should thus be further investigated to better identify the corresponding critical parameter combinations.

The EPRI Water Chemistry Guidelines are well-approved and operation praxis is often much better. Chloride content can be easily kept on a very low level and chloride transients, in contrast to sulphate excursions (e.g., form ion exchanger resin intrusions), are very rare events (very few leakage's with Ti or stainless steel condensers) and usually strongly limited in time (1 or 2 days). So far, there were no chloride-induced SCC cracking incidents in LAS primary pressure boundary components worldwide [1, 2]. It thus seems that the problem can be reasonably managed from a practical point of view.

The SCC testing also involved some conservatism. The chloride effects discussed in this paper are only valid for “deep" cracks and crevices, where significant chloride enrichment under oxidizing conditions and high plastic straining may simultaneously occur at the crack-tip/notch ground. Surface breaking defects in RPVs were very rare so far, but the RPV feedwater nozzle corner cracking by thermomechanical fatigue and EAC in BWRs [1, 2] or SCC in RPV penetration and attachment welds in BWRs and PWRs [3, 4] are some important exceptions. Furthermore, in case of dormant SCC cracks or for smooth and defect-free surfaces [14], a mechanical transient with significant plastic deformation were necessary to initiate fast SCC, at least at moderate chloride levels. The Swedish SCC test program in the Oskarshamn 3 BWR [25], on the other hand, indicated the possibility of onset of accelerated SCC crack growth even in passively loaded pre-cracked specimens, although with a much lower probability/frequency. During stationary power operation, pure static loading of vessels and most piping prevails, but the situation is different for start-up and shut-down and other important plant transients. Furthermore, the SCC tests were performed under quasi-stagnant or low-flow conditions; whereas in most plant locations, turbulent flow conditions prevail that reduce the potential chloride-enrichment in small surface defects. It is stressed that 5 to $10 \mathrm{ppb}$ of chloride resulted in significant acceleration of SCC crack growth by a factor of 3 to 10 in stainless steels and Ni-base alloys also [22, 31], the phenomenon 
is thus not restricted to LAS only. US BWR service clearly showed a significantly higher frequency of SCC incidents in plants with poor water chemistry/purity in early plant operation for stainless steel and various Ni-base alloys (e.g., Alloy 600) components [31].

Suggested modifications: The high-sulphur SCC line of the Ford \& Andresen model is recommend as the new BWR/NWC Disposition Line for crack growth during and a certain transition time after chloride transients of $\geq 3 \mathrm{ppb}$. An extension of the current transition time from 100 to $1000 \mathrm{~h}$ should be considered to better cover some potential long-term effects, although the data base is very small and further testing is clearly needed here. Such a modification and revision of BWRVIP-60 with consideration of the latest results is currently under discussion and in preparation at EPRI.

From an engineering point of view, the three Action Levels of the EPRI BWR Water Chemistry Guidelines and time intervals for corrective measures seem to be fairly appropriate although not always conservative in every situation with regard to chloride effects in NWC environment. A reduction of the Action Level 1 to 3 ppb of chloride could eventually be considered, if this threshold is further confirmed by current investigations in other labs. Continuous conductivity and periodic chloride measurements as well as intensified measurements of chloride in case of conductivity excursions seem to be appropriate. In any case, the duration of chloride transients should be kept as short as possible by corrective countermeasures and the potential impact of the chloride transient should be assessed by an engineering flaw tolerance evaluation. In case of very severe chloride transients, a controlled ordinary shut-down with slow cooling is recommended to fix the problem. The loading and opening of RPV cracks is significantly reduced and the thermo-mechanical loading of the cracks kept minimal.

\subsection{Mechanistic interpretation}

The main reason for the strong “anomalous” effect of chloride on SCC crack growth in RPV steels NWC environment is the very low SCC crack growth susceptibility and CGRs $\left(<1 \cdot 10^{-11} \mathrm{~m} / \mathrm{s}\right)$ at $K_{I^{-}}$values $<$ $60 \mathrm{MPa} \cdot \mathrm{m}^{1 / 2}$ in high-purity or sulphate containing oxygenated high-temperature water (Figure 18). Under these conditions with an aggressive sulphur-anion enriched occluded crack crevice chemistry, fast highsulphur SCC CGRs of the Ford \& Andresen Model [12] in the range of $6 \cdot 10^{-9} \mathrm{~m} / \mathrm{s}\left(20 \mathrm{MPa} \cdot \mathrm{m}^{1 / 2}\right)$ to $3 \cdot 10^{-}$ ${ }^{8} \mathrm{~m} / \mathrm{s}\left(60 \mathrm{MPa} \cdot \mathrm{m}^{1 / 2}\right.$ ) should prevail (Figure 18). But in reality, the initially fast high-sulphur EAC CGRs in the range of $10^{-9}$ to $10^{-7} \mathrm{~m} / \mathrm{s}$ cannot be sustained after switching from cyclic/slow rising load to constant load and cessation of SCC crack growth occurs within a few hundred hours with crack arrest or very slow SCC CGRs $<10^{-11} \mathrm{~m} / \mathrm{s}$ [7]. Furthermore, the decay of crack growth at the higher $K_{I}$-values often follows a reciprocal time law (Figure 19) indicating that crack growth and crack-tip strain rate could be controlled by low-temperature creep [7]. Sustained SCC crack growth at $K_{I}$-values $<60 \mathrm{MPa} \cdot \mathrm{m}^{1 / 2}$ (if it occurred at all) was usually very localized (some few isolated locations with very limited crack growth, often around MnS-inclusions which were intersected by the crack front) and could usually only be detected by post-test fractography with some very few exceptions [7]. Small amounts of chloride help to overcome the sustained cracking and crack-tip straining problems here and thus seem to have a tremendous effect (Figures 11 and 20). 


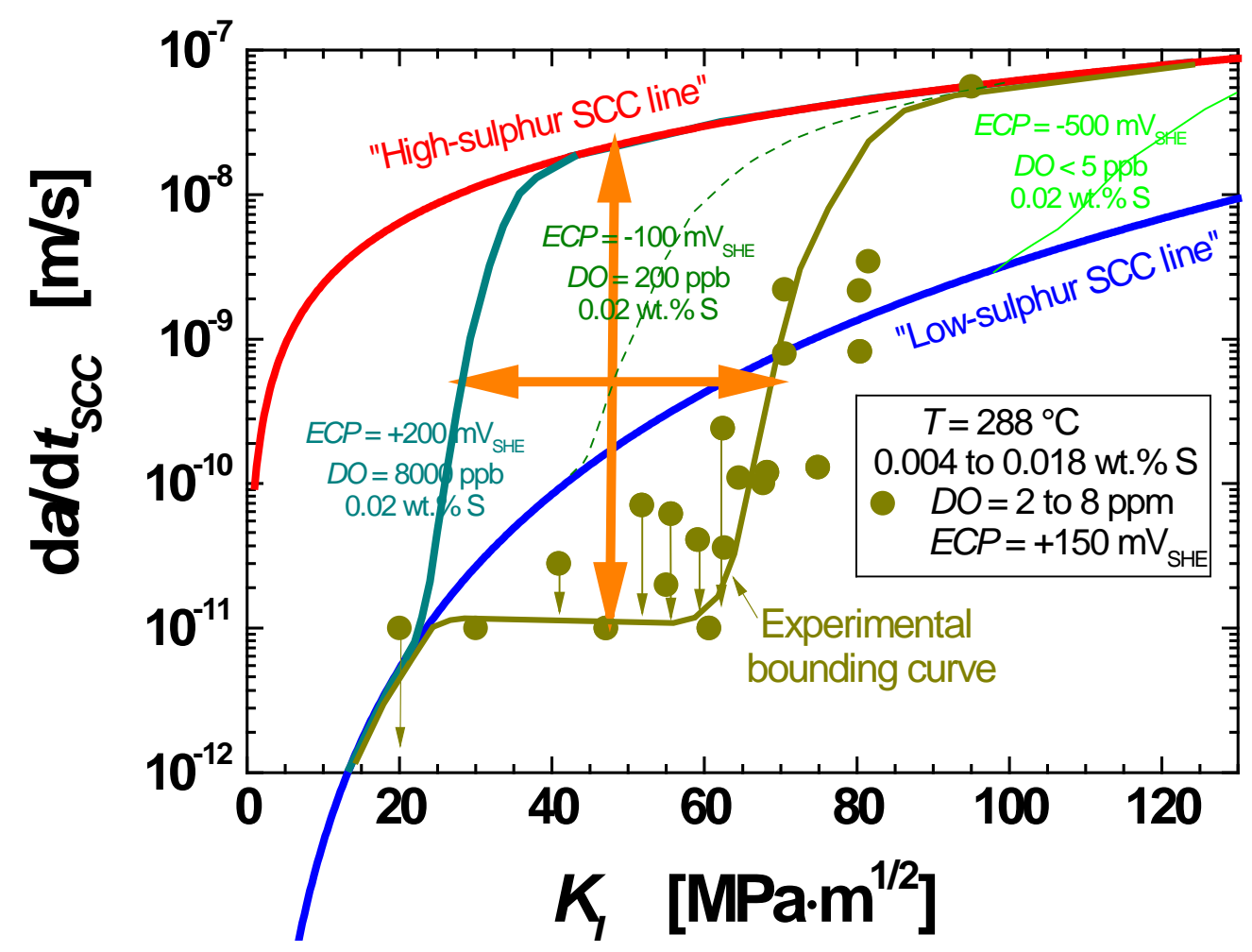

Figure 18: Comparison of low- and high-sulphur SCC line and transition curves for different ECPs of the F\&A model [12] with experimental SCC CGRs in chloride-free, oxygenated hightemperature water (down-pointing arrows indicate continuous cessation of SCC, see Figure 19) showing the large discrepancy between observed and expected/predicted behaviour.

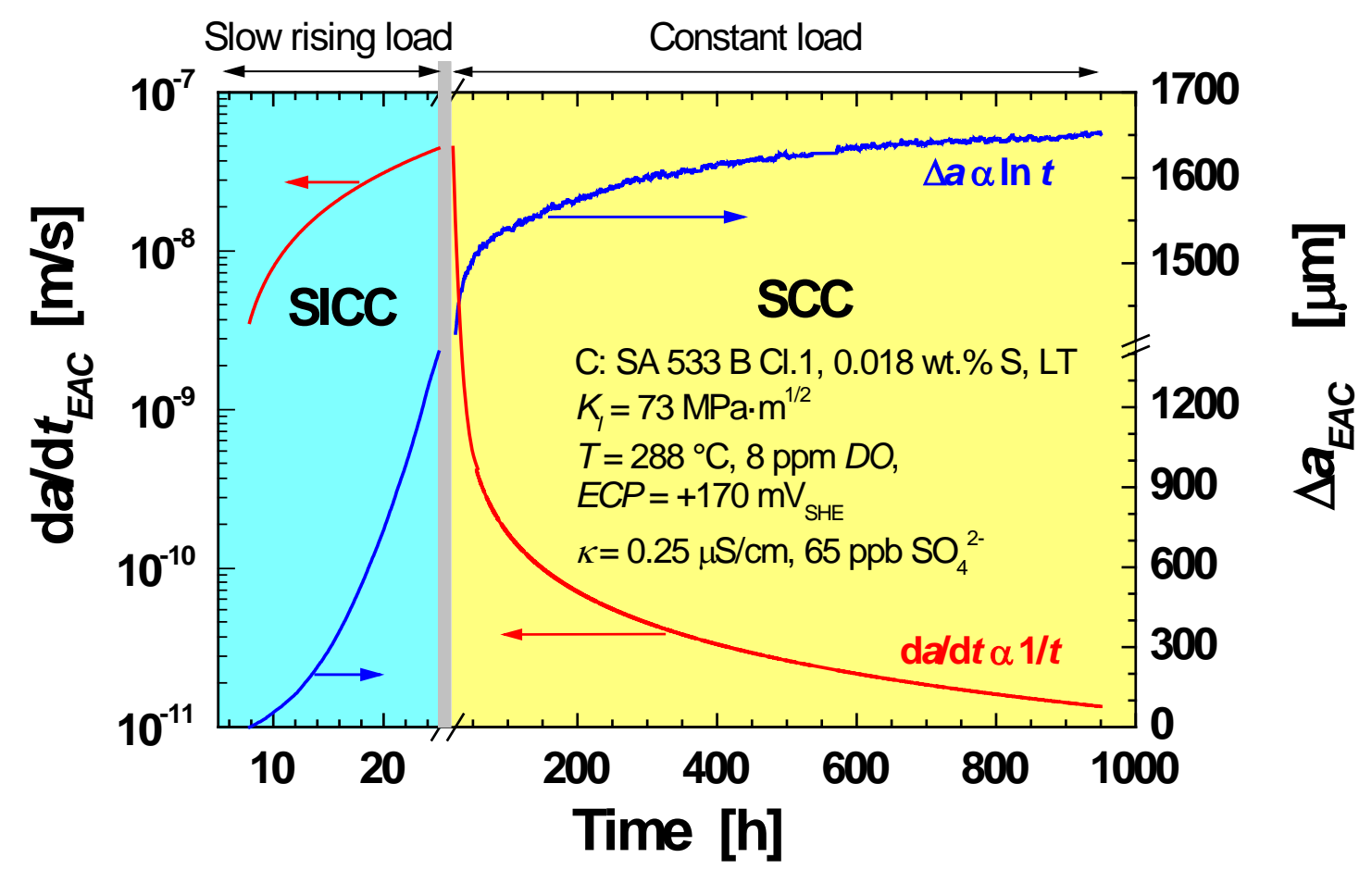

Figure 19: Decay of SCC CGR according to reciprocal time low at a high $K_{I}$ value of $73 \mathrm{MPa} \cdot \mathrm{m}^{1 / 2}$ after switching from slow rising to constant load indicating low-temperature creep controlled crack-tip strain rate and SCC crack growth. 
On the other hand, under conditions, where sustained (high-sulphur) EAC (e.g., under cyclic or slow rising load) or SCC crack growth prevail (e.g., at high $K_{I}$-values $>70 \mathrm{MPa} \cdot \mathrm{m}^{1 / 2}$ (Figure 11), in weld HAZ materials (Figures 15 and 20) with high hardness or in steels with high DSA susceptibility at intermediate temperatures), chloride has no or only a very minor accelerating effect on crack growth [19, 20]. Here a sustained crack-tip strain rate is assured by the external cyclic and slow rising load or facilitated by the very high load level and distinct low-temperature creep, steeper strain gradient at the crack-tip with higher yield stress (weld HAZ) and higher work hardening rate and localization of plastic deformation by DSA [1,2,7].

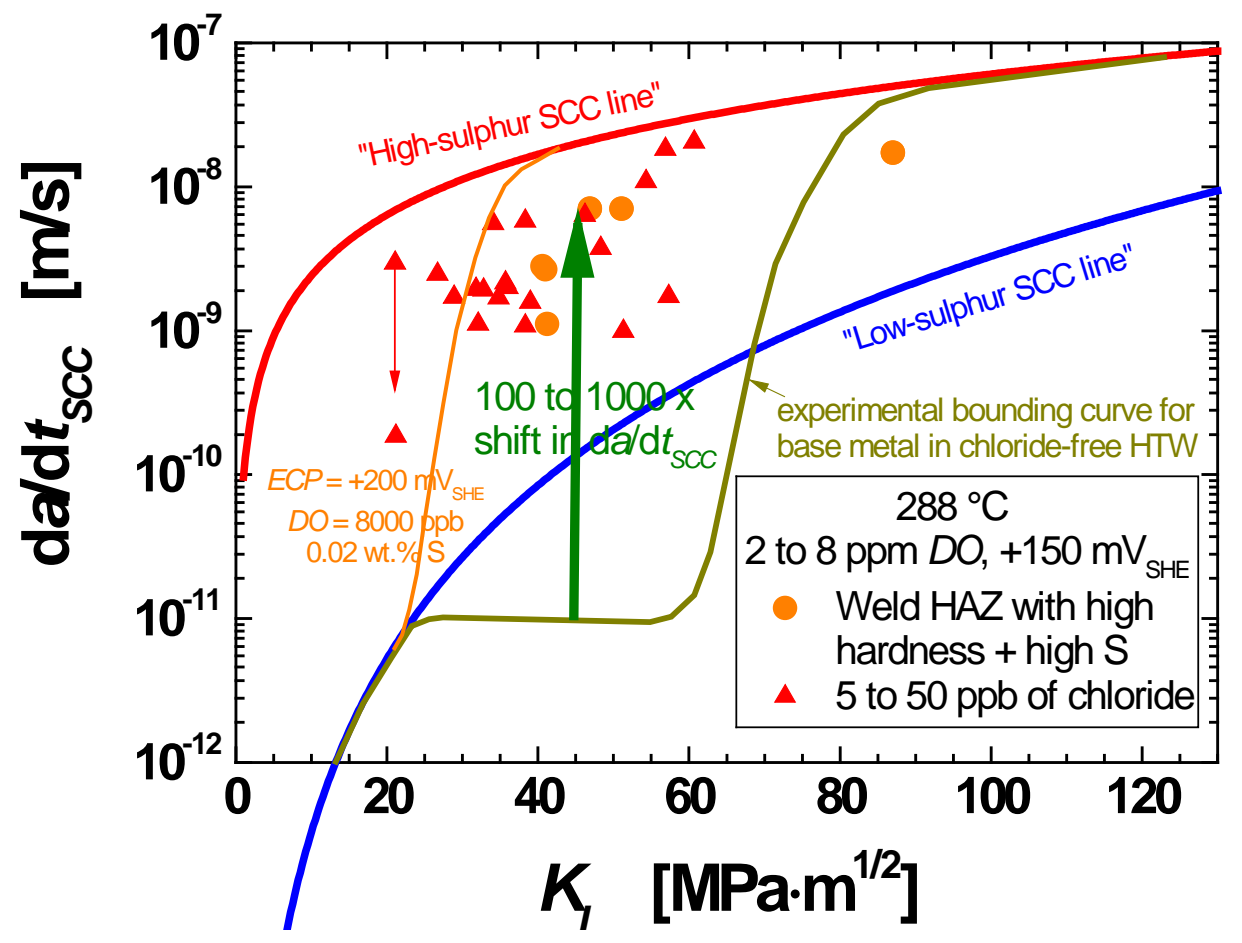

Figure 20: Reasonable prediction of SCC behaviour by Ford \& Andresen model in case of chloride addition or a high hardness weld HAZ material. Tremendous shift in SCC CGRs by small additions of chloride.

Film rupture/anodic dissolution mechanism according Ford \& Andresen: The observed SCC behaviour can be rationalized by the film rupture/anodic dissolution (FRAD) model of Ford \& Andresen [12] and crack crevice chemistry models [2, 22, 32, 33]. In the FRAD model [12], the protective oxide film formed on RPV steels in high-temperature water is ruptured by plastic straining at the crack-tip. The crack-tip then advances by anodic dissolution of the bare metal matrix. Anodic dissolution is slowed down and finally stopped by the nucleation and reformation of the oxide film ("repassivation"). Thus, continued crack advance will depend on a further oxide rupture process due to the action of a strain rate at the cracktip. The crack propagation rate is controlled by both anodic dissolution and repassivation kinetics and the frequency of oxide film rupture at the strained crack-tip. The first part is governed by the chemical composition of the local crack-tip electrolyte and the material. The second part is determined by the fracture strain of the oxide film and the crack-tip strain rate. In this model, there is a power law relationship between the crack growth rate and crack-tip strain rate, the amplitude being dependent on oxide film rupture strain and crack-tip environment/repassivation rate, the exponent being dependent on the environment/repassivation rate.

Under constant load, the crack-tip strain rate is governed by the crack growth rate into a less strainhardened region and the low-temperature creep that both are strongly dependent on the level of stress 
intensity factor. Under cyclic and slow rising load it is dominated by the applied stress intensity factor rate and crack growth rate. A higher yield stress and work hardening rate results in a higher crack-tip strain rate by crack growth due to the steeper strain gradient at the crack-tip [34]. DSA may result in the occurrence of a higher crack-tip strain/strain rate than for loading outside the DSA range, or than in a material which is not susceptible to DSA. The localisation of plastic deformation and increase in planar deformation from DSA further facilitates the mechanical rupture of the oxide film.

Sulphur-anions as $\mathrm{HS}^{-}, \mathrm{S}^{2-}$ and $\mathrm{SO}_{4}{ }^{2-}$ (as impurity in the bulk environment or from the dissolution of MnS-inclusions, which are intersected by the crack flanks and moving crack front) may significantly retard repassivation after oxide film rupture by their adsorption on the film-free surface [2, 12]. The sulphur-anion activity in the crack-tip environment increases with increasing steel sulphur content, concentration of sulphur-anions in the bulk environment outside the crack, crack growth rate (exposure of fresh, dissolvable MnS inclusions by the growing crack) and corrosion potential/dissolved oxygen content (enhanced migration of sulphur-anions towards the crack-tip).

The exponent of the crack growth rate-crack-tip strain rate power law relationship is dependent on the sulphide-anion activity in the crack-tip environment in the Ford \&Andresen model [12]. Above a sulphide concentration of $\sim 0.02 \mathrm{ppm}$ (low-sulphur threshold), the formation of a new oxide layer is increasingly delayed by increasing sulphide content, which thus leads to a larger increment of crack advance by anodic dissolution per oxide-rupture event. Above a sulphide content of $\sim 2 \mathrm{ppm}$ (highsulphur threshold), the sulphide effect on repassivation saturates. Based on this experimentally-derived relationship, lower and upper limiting EAC crack growth curves for LAS were defined (so-called lowand high-sulphur EAC lines in Figure 18). A critical, high sulphur-anion content of $\sim 2 \mathrm{ppm} \mathrm{S}^{2-}$ has to be maintained in the crack-tip electrolyte to sustain fast, high-sulphur EAC CGR rates, otherwise the CGRs quickly drop down to low-sulphur CGRs $[1,2,12]$. The corresponding transition from high- to low-sulphur behaviour is dependent on ECP, steel sulphur content and sulphate content of the environment (Figure 18).

In the Ford \& Andresen model, both crack-tip environment and crack-tip strain rate are dependent on crack growth rate and vice versa [2, 20]. This can result in significant positive feedback (higher crack growth rate $\rightarrow$ more aggressive crack-tip environment \& higher crack-tip strain rate $\rightarrow$ higher crack growth rate $\rightarrow \ldots$...) and hysteresis effects (e.g., in [9]), which may play an important role for the strong effect of chloride on SCC crack growth.

Chloride effects: In NWC environment, there is a migration-driven chloride enrichment in the crack crevice due to the potential gradient between the oxygenated crack-mouth and oxygen-depleted cracktip (Figure 21). Under steady state conditions, the migration flux of chloride towards the crack-tip and back diffusion flux out of the crack due to the chloride concentration gradient built-up in the crevice are equal. This typically results in a chloride and anion enrichment by a factor 10 to 50 (typically 20 to 30) depending on the $D O$ content $[1,2,25,28]$. Chloride, sulphate and other anion enrichments typically occur within some few to some few ten hours after anion addition. The initial crack crevice chemistry and chloride content is re-established after some few 10 to 100 hours after returning to high-purity water. In HWC environment (no potential gradient in crack crevice), the mass transport is only diffusion-driven with little enrichment and the situation with regard to transients is thus quite symmetric (Figure 21). These observations were confirmed by micro-sampling experiments [27, 35, 36]. 
BWR NWC:

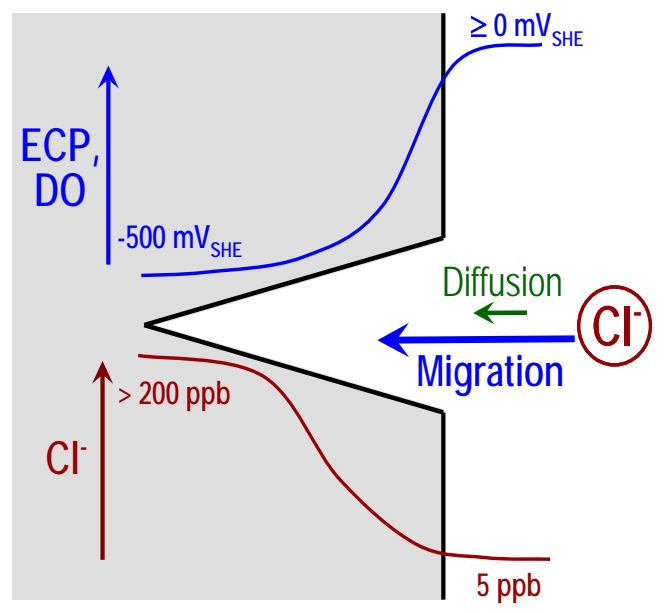

BWR HWC:

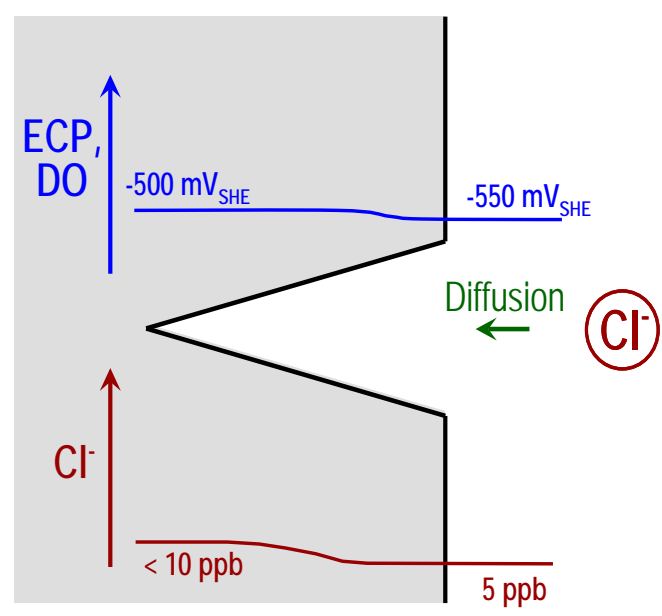

Figure 21: Schematic of the mass transport of chloride ions in long cracks under oxidizing BWR NWC and reducing HWC conditions.

With bulk chloride contents of up to $100 \mathrm{ppb}$ and an enrichment factor of 20 to 30, there is only a very slight acidification of the crack-tip environment (pH-shift at temperature of 1 to 1.5 units at maximum). This moderate acidification results in an higher anodic dissolution rate and slight retardation of repassivation and thus larger crack advance after an oxide film rupture. The dissolution of MnSinclusions, which are intersected by the crack front and flanks might be slightly accelerated also (and there might thus be a synergy with the steel sulphur content). This might further amplify the acidification and, in particular, further significantly retard the repassivation by the adsorption of sulphides at the bare crack-tip metal. Scratch/repassivation measurements revealed only a minor effect of chloride on repassivation [14, 37], in contrast to the sulphides [1, 12].

Chloride seems to reversibly adsorb on/in the oxide film and to alter the oxide film properties [27], which either could result in lower film rupture strains, less protective oxide layers or even in an (electro)chemical break-down of the film. Thinner oxide films were observed in chloride containing hightemperature water [27], which facilitates film rupture by plastic slip at smaller strains. Stronger localized thinning of oxide film was observed for long exposure times in high chloride environments including pitting [27]. These effects increase the oxide film rupture frequency and thus crack growth rate.

In chloride-free NWC environment at $K_{I}$-values $<60 \mathrm{MPa} \cdot \mathrm{m}^{1 / 2}$, the SCC crack advance by anodic dissolution under constant load between two film ruptures is only marginally too small to induce sufficient straining for a new rupture and the crack-tip strain rate and crack growth rate are thus controlled by the declining low-temperature creep solely. The acidification of the crack crevice environment due to chloride results in a higher metal dissolution rate after rupture of the protecting oxide film and in a further delay of the repassivation of the metal. This results in a moderately larger SCC crack growth increment due to anodic dissolution of the metal. The less protecting, thinner oxide film with smaller film rupture strain due to chloride adsorption decreases the necessary crack advance to induce sufficient straining for a new film rupture. Together with the previously mentioned positive feedback effects and above a certain critical crack-tip chloride content threshold, this results in an acceleration of SCC crack growth that may be fast enough to establish a sustained dynamic equilibrium between crack-tip straining and crack growth with high-sulphur SCC crack growth under static load. Above the critical crack-tip environment chloride concentration, a further increase in the bulk chloride concentration does not further accelerate SCC crack growth. At higher ECPs, less chloride in the bulk environment is necessary to exceed the critical crack- 
tip environment concentration due to the stronger chloride enrichment in the crack crevice. At lower stress intensity factors, the crack-tip strain accumulation due to low-temperature creep is lower and a somewhat higher critical crack-tip chloride concentration is necessary to establish fast high-sulphur SCC crack growth.

\section{Conclusions}

The SCC growth behaviour in low-alloy RPV steels and perpendicular to the fusion boundary in Alloy 182-RPV steel dissimilar metal weld joints was evaluated and assessed under simulated BWR NWC and HWC conditions with different contents of chloride impurities. The chloride was added either continuously or in the form of temporary transients.

In BWR NWC environment, small amounts of chloride ( $\geq 3 \mathrm{ppb}$ ) may result in acceleration of the SCC crack growth by at least one order of magnitude and in fast stationary SCC under constant load close to the "high-sulphur SCC crack growth curve" of the Ford \& Andresen model. For 3, 5 and 10 ppb of chloride, SCC crack growth through the fusion boundary into the adjacent RPV steel in DMWs occurred at least down to stress intensity factors of 50,30 and $20 \mathrm{MPa} \cdot \mathrm{m}^{1 / 2}$, respectively. In BWR HWC environment, a much higher chloride tolerance was observed, where even $100 \mathrm{ppb}$ of chloride were not sufficient to induce SCC below $60 \mathrm{MPa} \cdot \mathrm{m}^{1 / 2}$.

In case of chloride transients, the addition of $\geq 3 \mathrm{ppb}$ chloride may result in fast SCC after rather short incubation periods of a few hours in NWC environment. In case of dormant non-growing cracks under constant load an additional "activation" of the crack-tip was necessary by a single un- and reloading event. After moderate $(\leq 10 \mathrm{ppb})$ and short-term $(\leq 100 \mathrm{~h})$ chloride transients the SCC CGRs drop below $0.5 \mathrm{~mm}$ /year within few 10 hours to few 100 hours after returning to high-purity water and cessation generally occurs. Possible long-term effects with accelerated SCC rates above the "low-sulphur SCC crack growth curve” of the Ford \& Andresen model cannot be fully excluded after prolonged ( $\geq 200 \mathrm{~h}$ ) and severe ( $\geq 15 \mathrm{ppb}$ ) chloride transients and such long-term effects should be further evaluated.

\section{Acknowledgement}

The data of this paper have been generated within the RIKORR, CASTOC, KORA and SAFE projects. The financial support for these projects by the Swiss Federal Nuclear Safety Inspectorate (ENSI), the Swiss Federal Office of Energy, Swissnuclear and the Swiss Federal Office for Education and Science is gratefully acknowledged. Thanks are also expressed to U. Ineichen, U. Tschanz, B. Gerodetti, L. Nue, B. Baumgartner, R. Schwenold and E. Groth ${ }^{\dagger}$ (all PSI) for their experimental contribution to this work.

\section{References}

1. H.P. Seifert, J. Hickling, and D. Lister, Corrosion and environmentally-assisted cracking of carbon and low-alloy steels, in: Comprehensive Nuclear Materials, Editor R.J.M. Konings, Elsevier: Oxford, UK, ISBN: 978-0-08-056033-5, pp. 105-142, 2012.

2. H.P. Seifert, S. Ritter, Research and service experience with environmentally-assisted cracking of carbon \& low-alloy steels in high-temperature water, SKI-Report 2005:60, ISSN 1104-1374, SKI, Stockholm, Sweden, 2006.

3. H.P. Seifert, S. Ritter, T. Shoji, Q.J. Peng, Y. Takeda, Z.P. Lu, Environmentally-assisted cracking behaviour in the transition region of an Alloy 182/SA $508 \mathrm{Cl} .2$ dissimilar metal weld joint in 
simulated boiling water reactor normal water chemistry environment, Journal of Nuclear Materials 378 (2008) $197-210$.

4. H.P. Seifert, S. Ritter, H.J. Leber, Stress corrosion cracking behaviour in the transition region of Alloy 182 / low-alloy reactor pressure vessel steel dissimilar metal weld joints in light water reactor environments, Corrosion 71 (2015) 433-454.

5. S. Roychowdhury, H.P. Seifert, P. Spätig, Z. Que, S. Ritter, Effect of high temperature water and hydrogen on the fracture behaviour of a low-alloy reactor pressure vessel steel, in: $17^{\text {th }}$ International Conference on Environmental Degradation of Materials in Nuclear Power Systems - Water Reactors, CNS, Ottawa, Ontario, Canada, August 9-13, 2015.

6. S. Roychowdhury, H.P. Seifert, P. Spätig, Z. Que, S. Ritter, Effect of high temperature water and hydrogen on the fracture behaviour of a low-alloy reactor pressure vessel steel, accepted for publication in Journal of Nuclear Materials, 2016.

7. H.P. Seifert, S. Ritter, Stress corrosion cracking of low-alloy reactor pressure vessel steels under boiling water reactor conditions, Journal of Nuclear Materials 372 (2008) 114 - 131.

8. H.P. Seifert, S. Ritter, Strain-induced corrosion cracking behaviour of low-alloy steels under boiling water reactor conditions, Journal of Nuclear Materials 378 (2008) 312 - 326.

9. H.P. Seifert, S. Ritter, Corrosion fatigue crack growth behaviour of low-alloy reactor pressure vessel steels under boiling water reactor conditions, Corrosion Science 50 (2008) 1884 - 1899.

10. H. Hänninen, H.P. Seifert, Y. Yagodzinsky, U. Ehrnstén, O. Tarasenko, P. Aaltonen, Effects of dynamic strain ageing on environment-assisted cracking of low alloy pressure vessel and piping steels, in: $10^{\text {th }}$ Int. Conf. on Environmental Degradation of Materials in Nuclear Power Systems Water Reactors, NACE/TMS/ANS, Lake Tahoe, Nevada, USA, August 6 - 10, 2001.

11. F.P. Ford, R.M. Horn, J. Hickling, R. Pathania, Stress corrosion cracking of low alloy steels under BWR conditions; assessments of crack growth rate algorithms, in: $9^{\text {th }}$ International Conference on Environmental Degradation of Materials in Nuclear Systems - Water Reactors, NACE/TMS/ANS, Newport Beach, CA, USA, August 1 - 5, 1999.

12. F.P. Ford, Environmentally assisted cracking of low-alloy steels, EPRI NP-7473-L, Electric Power Research Institute, Palo Alto, CA, USA, January 1992.

13. B. Cheng, et al., BWR water chemistry guidelines - 1996 revision, EPRI TR-103515-R1, Electric Power Research Institute, Palo Alto, CA, USA, December 1996.

14 P.L. Andresen, Effects of specific anionic impurities on environmental cracking of austenitic materials in $288^{\circ} \mathrm{C}$ water, Proc. of $5^{\text {th }}$ International Symposium on Environmental Degradation of Materials in Nuclear Power Systems - Water Reactors, Monterey, California, USA, August 25-29, 1991, ANS, pp. 209-218.

15. P.L. Andresen, Transition and delay time behaviour of high-temperature crack propagation rates resulting from water chemistry changes, Proc. $2^{\text {nd }}$ International Symposium on Environmental Degradation of Materials in Nuclear Power Systems - Water Reactors, Monterey, CA, USA, 9-12 September 1985, ANS, pp. 84-92.

16. W.E. Ruther, W.K. Soppet, T.F. Kassner, Effect of temperature and ionic impurities at very low concentrations on SCC of sensitized type 304 SS, Corrosion 40 (1984) 791-799.

17. L. Ljungberg, D. Cubicciotti, M. Trolle, Effects of impurities on the IGSCC of stainless steel in hightemperature water, Corrosion 44 (1988) 66-72. 
18. B. Gordon, S. Garcia, Technical basis for water chemistry control of IGSCC in boiling water reactors, 15th International Conference on Environmental Degradation, Colorado Springs, Colorado, USA, August 7-11, 2011, TMS, pp. 2061-2076.

19. S. Ritter, H.P. Seifert, The effect chloride impurities on the EAC initiation in low-alloy RPV steels in high-temperature water, submitted to Corrosion, 2016.

20. H.P. Seifert, S. Ritter, The effect of ppb levels of chloride impurities on the corrosion fatigue and SICC crack growth beahviour of low-alloy RPV steels in high-temperature water, submitted to Corrosion Science, 2015.

21. A. Turnbull, Modelling of environment assisted cracking, Corrosion Science 34 (1993) 921-960.

22. P.L. Andresen and L.M. Young, Characterization of the role of electro-chemistry, convection and crack chemistry in stress corrosion cracking, in: $7^{\text {th }}$ International Conference on Environmental Degradation of Materials in Nuclear Systems - Water Reactors, NACE/TMS/ANS, Breckenridge, Colorado, USA, August 6-10, 1995.

23. A. Turnbull, Modelling of crack chemistry in sensitized stainless steel in boiling water reactor environments, Corrosion Science 39 (1997) 789-805.

24. A. Turnbull, M. Psaila-Dombrowski, A review of electrochemistry of relevance to environmentassisted cracking in light water reactors, Corrosion Science 33 (1992) 1925-1966.

25. H.P. Seifert, S. Ritter, Review and assessment of SCC experiments with RPV steels in Oskarshamn 2 and 3 (ABB Report SBR 99-020), SKI Report 2005:61, Stockholm, Sweden, 2006.

26. M. Herbst, A. Roth, M. Widera, E. Nowak, Effects of chloride on the EAC-behaviour of low-alloy steels in oxygenated high-temperature water, in: $16^{\text {th }}$ International Conference on Environmental Degradation of Materials in Nuclear Power Systems - Water Reactors, NACE/TMS/ANS, August 11-15, 2013, Asheville, North Carolina.

27. M. Herbst, Effect of chloride on environmentally assisted cracking of low alloy steels in oxygenated high temperature water, PhD thesis, Liverpool John Moores University, 2013.

28. K.H. Herter, X. Schuler, T. Weissenberg, Crack growth behaviour of ferritic pressure vessel steels in oxygenated high temperature water under transient loading. in: ASME 2013 Pressure Vessel and Piping Conference, ASME, Paris, France, July 14-18, 2013.

29. K. Kumagai, M. Morra, P.L. Andresen, G. Catlin, L. Nelson, S. Suzuki, Y. Takagi, R. Horn, Effects of $\mathrm{K}$ and anion impurity concentration on crack growth kinetics near alloy 182/A533B weld overlay boundaries in BWRs, in: $14^{\text {th }}$ International Conference on Environmental Degradation of Materials in Nuclear Systems - Water Reactors, NACE/TMS/ANS, Virginia Beach, Virginia, USA, August 23-27, 2009.

30. X. Lou, P.L. Andresen, T. Lian and R. Pathania, Effect of ppb levels of chloride on the stress corrosion cracking of pressure vessel steel, in: $17^{\text {th }}$ International Conference on Environmental Degradation of Materials in Nuclear Power Systems - Water Reactors, CNS, Ottawa, Ontario, Canada, August 9-13, 2015.

31. P.L. Andresen, Stress corrosion cracking (SCC) of austenitic stainless steels in high temperature light water reactor (LWR) environments, in: Understanding and Mitigating Ageing in Nuclear Power Plants Materials and Operational Aspects of Plant Life Management (PliM), Ed.: Ph.G. Tipping, Woodhead Publishing/Elsevier, Cambridge, UK, October 2010, ISBN: 978-1-84569-511-8, pp. 236307. 
32. P.L. Andresen, Modelling the effect of sulphur on the threshold environmental cracking rate of steels in high temperature water, in: $3^{\text {rd }}$ International Conference on Fatigue and Fatigue Thresholds, Midlands, UK, 1987, pp. 1189-1200.

33. P.L. Andresen, Modelling of water and material chemistry effect on crack-tip chemistry and resulting crack growth kinetics, in: ${ }^{3 r}$ d International Symposium on Environmental Degradation of Materials in Nuclear Systems - Water Reactors, TMS-AIME, Traverse City, MI, USA, August 30-September 3, 1988, pp. 301-312.

34. T. Shoji, Z. Lu, H. Murakami, Formulating stress corrosion cracking growth rates by combination of crack tip mechanics and crack tip oxidation kinetics, Corrosion Science, 52 (2010) 769-779.

35. P.L. Andresen, L.M. Young, Crack-tip microsampling and growth rate measurements in low-alloy steel in high-temperature water, in: NACE Corrosion 1995, NACE, Orlando, Florida, March 26 -31, 1995, Paper No. 156.

36. P. L. Andresen, L. M. Young, Crack tip microsampling and growth rate measurements in low-alloy steel in high-temperature water, Corrosion 51 (1995) 223 - 233.

37. S. Ritter, H.P. Seifert, Current measurements during scratching of low-alloy steel in simulated BWR environment, in: Annual Meeting of the European Cooperative Group on Corrosion Monitoring of Nuclear Materials, WG1-3 (CD-ROM), Paris, France, June 10-11, 2013. 